\title{
Reconocimiento de la biodiversidad urbana para la planeación en contextos de crecimiento informal ${ }^{\star}$
}

\begin{tabular}{|l|l|}
\hline Fecha de recepción: 20 de noviembre de 2015 Fecha de aceptación: 19 de julio de 2016 Disponible en línea: 30 de octubre de 2016 \\
\hline Juliana Montoya \\
\hline Arquitecta con maestría en conservación y uso de biodiversidad & Investigadora del Instituto Humboldt \\
\hline Lider de la línea de biodiversidad en entornos urbano-regionales \\
\hline Pontificia Universidad Javeriana & juliana.montoya@javeriana.edu.co jmontoya@humboldt.org.co \\
\hline
\end{tabular}

Resumen Vivimos en un mundo cada vez más urbano que ejerce una presión sin precedentes sobre los ecosistemas. Este panorama presenta un desafío urgente en cuanto a la conservación de la biodiversidad y de muchos servicios de los ecosistemas de los que la sociedad depende. Desafortunadamente, la importancia de la biodiversidad y los beneficios que obtenemos no representan una preocupación inmediata para los aproximadamente 900 millones de personas que viven en barrios marginales, sin servicios básicos, en viviendas precarias y en condiciones de vida insalubres. Esta revisión intenta dar respuesta a cómo integrar la biodiversidad urbana a los asentamientos precarios por medio del análisis comparativo de ciudades, el estudio de criterios y herramientas de planeación, y propuestas de acciones locales para la biodiversidad en contextos informales. Estas acciones están compuestas por un kit de herramientas que presenta la convergencia territorial y social mediante referentes exitosos de cómo integrar el desafío que constituye la pobreza y la degradación de nuestros ecosistemas.

Palabras clave biodiversidad urbana; acciones locales; ciudades; asentamientos precarios; planeación urbana; servicios ecosistémicos urbanos

\footnotetext{
* Articulo de Investigación clentffica producto del trabajo de grado para optar al título de magister en Conservación y Uso de Biodlversidad.
}

Cómo citar este artículo: Montoya, J. (2016). Reconocimiento de la blodiversidad urbana para la planeación en contextos de crecimiento informal. Cuadernos de Vivienda y Urbanismo, 9(18), 232-275. http://dx.dol.org/10.11144/Javeriana.cvu9-18.rbup 


\section{Recognizing of Urban Biodiversity for Territorial Planning from Informal Settlements}

Abstract We live in an increasingly urban world that puts an unprecedented pressure on ecosystems. This trend presents an urgent challenge in terms of conservation of the biodiversity and many of the ecosystem services on which society depends. Unfortunately, the importance of biodiversity and the benefits we get from it do not represent an immediate concern for the approximately 900 million people living in slums without basic services, poor housing and unsanitary living conditions. This review attempts to tackle the question of how to integrate urban biodiversity into slums contexts through a comparative analysis of cities, the study of planning tools and criteria and the proposal of local actions for biodiversity in informal settlements. These actions are composed by a toolkit that presents, the territorial and social convergence through successful examples of integrating the challenges of poverty and degradation of our ecosystems.

Keywords urban biodiversity; local actions; cities; informal settlements; urban planning; urban ecosystem services

\section{Reconhecimento da biodiversidade urbana para o planejamento em contextos de crescimento informal}

Resumo Vivemos num mundo cada vez mais urbano o que exerce pressão sem precedentes sobre os ecossistemas. Este panorama representa um desafio urgente em termos de conservação da biodiversidade e muitos dos serviços dos ecossistemas dos quais a sociedade depende. Infelizmente, a importância da biodiversidade e os benefícios que recebemos não representam uma preocupação imediata para os cerca de 900 milhóes de pessoas que vivem em favelas sem serviços básicos, condições precárias de habitação e condiçôes de vida insalubres. Esta revisão tenta abordar a questão de como integrar a biodiversidade em favelas urbanas através da análise comparativa de cidades, o estudo de critérios e ferramentas de planejamento, e propostas de açóes locais para a biodiversidade em contextos informais. Para isso é usado um kit de ferramentas, com as quais qualquer residente tem na máo uma gama de oportunidades, e referências bem-sucedidas, que permitem integrar o desafio da pobreza e a degradaçáo de nossos ecossistemas. 


\section{Introducción}

Las tendencias del crecimiento poblacional proyectan que para el año 2050 tendremos 6,3 millones de habitantes urbanos, casi el doble de lo que se informó para el 2010 (United Nations [UN], 2014); esto afecta los ecosistemas aledaños debido a la transformación generada por la expansión urbana y por la creciente demanda de recursos para la vida diaria. Este crecimiento urbano trae consecuencias significativas para la biodiversidad y los servicios de los ecosistemas (Convention on Biological Diversity [CBD], 2012).

En cuanto a América Latina, más del $80 \%$ de la población vive en ciudades y se proyecta que para el año 2050 alcance el $90 \%$, por lo que será la región más urbanizada del mundo (UN, 2014). Esta situación se agrava por el hecho de que en América Latina la planificación territorial no está integrada a temas de diversidad biológica, y a los servicios de los ecosistemas, con precios de la tierra que no reflejan su valor ecológico. Las mal llamadas zonas 'marginales', como humedales, laderas, retiros de quebrada, entre otros (CBD, 2012), son el lugar propicio para el crecimiento informal caracterizado por asentamientos precarios que intervienen el entorno natural. Varios trabajos científicos recientes, así como algunas iniciativas desde la institucionalidad pública en las ciudades, han puesto de relieve la importancia de la biodiversidad urbana dentro de la escala global y lo relevante que será la aplicación del Convenio de Diversidad Biológica en los pueblos, las ciudades y las aglomeraciones urbanas (Müller, Werner y Kelcey, 2010; Alberti et al., 2003; Local Governments for Sustainability [ICLEI], 2010). Ejemplos de esta aplicación son la política pública de ecourbanismo y construcción sostenible en Bogotá (Alcaldía Mayor de Bogotá, Secretaría Distrital de
Ambiente, Secretaría Distrital de Hábitat, Secretaría Distrital de Planeación, 2014) y la propuesta para la gestión integral de la biodiversidad para Medellín (Alcaldía de Medellín, Secretaría de Medio Ambiente, Parque Explora, Instituto de Investigación de Recursos Biológicos Alexander von Humboldt, Jardín Botánico de Medellín, Parques Nacionales Naturales de Colombia, Sociedad Antioquena de Ornitología, 2014).

Por lo tanto, se plantea una cuestión principal: ¿cómo integrar la biodiversidad urbana a los contextos de crecimiento informal en las ciudades? En una primera parte, esta revisión buscará dar respuesta, al profundizar en las presiones de la urbanización formal e informal, en las motivaciones para conservar la biodiversidad urbana. En la segunda parte, se explorará la integralidad de los conceptos de biodiversidad urbana y los servicios de los ecosistemas, por medio de la descripción de los diferentes enfoques que pueden tener en la sociedad. En la tercera parte, se compararán tres ciudades mediante fichas de análisis. En la cuarta parte, se recopilarán los criterios y herramientas de planeación de cada una de ellas, utilizadas desde la biodiversidad urbana y desde el crecimiento informal, propuestas en su mayoría por gobiernos u organizaciones (top down) y algunas pocas desde las comunidades (bottom $u p$ ). La última parte reúne estos flujos de relaciones (desde bottom up y top down) para incorporarlos en acciones locales para la biodiversidad en contextos de crecimiento informal por medio de un kit de herramientas y una discusión de cómo las ciudades pueden integrarlos en su planeación, poniéndolos en conocimiento de sus habitantes, en busca de un escenario más equilibrado entre la conservación, el uso de la biodiversidad y el bienestar humano. 


\section{Metodología}

Para el desarrollo del proceso metodológico se adoptarán las siguientes definiciones:

\begin{tabular}{|c|c|}
\hline $\begin{array}{c}\text { Biodiversidad } \\
\text { urbana }\end{array}$ & $\begin{array}{l}\text { Es la variedad y riqueza de organismos vivos y la diversidad de ecosistemas encontrados dentro } \\
\text { y afuera de las ciudades, en dónde las sociedades humanas configuran el territorio y, por lo tanto, } \\
\text { establecen los hábitats y las condiciones para la supervivencia de estas formas de vida. }\end{array}$ \\
\hline \multicolumn{2}{|r|}{ The Erfurt Declaration [Urbio] (2008) CBD (2012) Alcaldía de Medellín et al., 2014} \\
\hline $\begin{array}{l}\text { Servicios } \\
\text { ecosistémicos } \\
\text { urbanos }\end{array}$ & $\begin{array}{l}\text { Son los beneficios directos e indirectos de la biodiversidad para el bienestar humano. Las ciudades } \\
\text { dependen de los ecosistemas dentro y fuera del entorno urbano para una amplia variedad de } \\
\text { bienes y servicios, que son esenciales para la sostenibilidad económica, social y ambiental. }\end{array}$ \\
\hline \multicolumn{2}{|r|}{ The Economics of Ecosystems and Biodiversity [TEEB] (2010) Rincón-Ruiz (2014) MEA (2005) } \\
\hline $\begin{array}{l}\text { Crecimiento } \\
\text { informal }\end{array}$ & $\begin{array}{l}\text { Son las zonas donde se combinan deficiencias en el acceso al agua potable, a servicios de saneamiento, } \\
\text { mala calidad estructural de las viviendas, hacinamiento y tenencia ilegal de la tierra. Estos sectores } \\
\text { marginales constantemente reciben nueva población, a pesar de presentar malas condiciones de } \\
\text { habitabilidad y pobreza. El crecimiento informal está asociado en algunas regiones a lo que se denomina } \\
\text { como tugurios, favelas, villas, comunas, rancherías, slum, shack, asentamientos precarios, entre otros. }\end{array}$ \\
\hline \multicolumn{2}{|r|}{ El Sioufi (2013) UN-Habitat (2014) } \\
\hline $\begin{array}{l}\text { Planeación } \\
\text { urbana }\end{array}$ & $\begin{array}{l}\text { Son las herramientas que facilitan a las ciudades y a los gobiernos locales la aplicación } \\
\text { de criterios o principios sobre el territorio. La biodiversidad urbana está determinada } \\
\text { por la planificación, diseño y gestión del entorno construido que, a su vez, influencia los } \\
\text { valores y dinámicas económicas, sociales y culturales de la población humana. }\end{array}$ \\
\hline \multicolumn{2}{|r|}{ Müller et al., (2010) de Oliveira (2011) } \\
\hline Hábitat urbano & $\begin{array}{l}\text { Es la diversidad espacial compuesta por comunidades de plantas y estructuras vivas o inertes, } \\
\text { las cuales van desde la periferia rural al núcleo urbano, e incluye: la vegetación remanente, } \\
\text { los paisajes agrícolas, paisajes urbano-industriales y jardines y espacios verdes. }\end{array}$ \\
\hline \multicolumn{2}{|r|}{ Faeth et al., (2011) CBD (2012) } \\
\hline Ecosistemas urbanos & $\begin{array}{l}\text { Es necesario estudiar las ciudades como ecosistemas, en donde la población humana, en } \\
\text { una configuración de edificios, infraestructura y espacios abiertos, establece efectos sobre el } \\
\text { clima local, los suelos, el agua y la biodiversidad de acuerdo con el gradiente de urbanización; } \\
\text { e influencia toda la biosfera con sus inmensos flujos de entrada y de salida. }\end{array}$ \\
\hline \multicolumn{2}{|r|}{ Soares (2012) Müller et al., (2010) Savard, Clergeau y Mennechez (2000) } \\
\hline
\end{tabular}

Esta revisión aborda algunas consideraciones negativas acerca de las presiones sobre la biodiversidad que ejercen el crecimiento poblacional, la expansión urbana, el crecimiento informal, la pobreza, el desconocimiento de los servicios de los ecosistemas y la planeación urbana limitada. Luego se contrastará con las visiones positivas del papel fundamental que cumplen las ciudades por medio de algunas motivaciones para conservar la biodiversidad urbana al reconocer los procesos ecológicos, los servicios de los ecosistemas, el bienestar humano que genera y, finalmente, esbozará la gran tarea que tienen las ciudades con la planeación urbana y la gestión integral para su uso y conservación.

Para finalizar la primera fase conceptual, se hace una revisión de la literatura relacionada con biodiversidad urbana y servicios ecosistémicos con el fin de elaborar una matriz de enfoques 
(científico, cultural, social, económico, cambio climático, político, planeación urbana y una última sección que contextualiza el caso colombiano). En la segunda fase de esta investigación se presentan las fichas de análisis de ciudades que, por su condición de alta biodiversidad y tendencias de crecimiento informal, representan una oportunidad con respecto a sus experiencias en planeación por medio de la priorización de criterios (principios orientadores de ciudad) y herramientas (instrumentos de implementación de los criterios) que pretenden materializar el modelo de ocupación de cada ciudad.

A partir de los principales hallazgos producto de los análisis de las ciudades, se sintetizan los criterios y las herramientas de planeación que intentan resolver la integración de la biodiversidad urbana y el crecimiento informal en las ciudades. Para lograr esto, se profundiza en los flujos de relaciones desde iniciativas de la comunidad (bottom up) enfocados en la inclusión del crecimiento informal, en contraste con iniciativas de gobierno (top down) orientadas a la planeación de la biodiversidad urbana. Se busca lograr la convergencia de ambos flujos, por medio de una gobernanza integral. Para esto se proponen trece acciones locales para la biodiversidad en contextos informales, que presentadas a modo de kit de herramientas, explican mediante casos de estudio cómo podría ser la integración del uso y conservación de la biodiversidad urbana en estos contextos.

\section{Procesos de urbanización y consecuencias para la biodiversidad}

Aunque los paisajes urbanos ocupan solo el $4 \%$ de la superficie terrestre (UN, 2008), el $75 \%$ de la población en los países desarrollados vive en asentamientos urbanos. Sin embargo, los impactos de las ciudades se extienden mucho más allá de los límites urbanos ya que estas no son entidades autónomas ni discretas, son más bien nodos de actividad, que debido a las dinámicas de sus habitantes, demandan grandes cantidades de recursos naturales, que producen enormes cantidades de residuos, que interactúan profundamente con sus biorregiones circundantes y que alteran considerablemente los ecosistemas cercanos y lejanos (ICLEI, 2010 y Williams, 2012).

El crecimiento urbano significa que el medio ambiente natural es ocupado cada vez más con edificios, vías de circulación y otras construcciones (Elander, Alm, Malbert, Sandström, 2005), lo que implica un gradiente de influencia humano desde los centros urbanos hacia las zonas rurales de la periferia (Yokohari, Takeuchi, Watanabe, Yokota, 2000). Esto sin considerar aún la dinámica dominante de la expansión de las ciudades que tiene que ver con el crecimiento informal, esa condición injusta que representa la pobreza y que hace complejo cualquier escenario (PNUD, 2014). La ONU, según el objetivo 1 de los Objetivos de Desarrollo del Milenio, registra que 1.200 millones de personas viven con menos de 1,25 dólares al día (UN, 2005).

\section{Crecimiento poblacional \\ y expansión urbana}

Actualmente, la dinámica poblacional apunta a un mundo cada vez más urbano (ver Figura 1), en donde el crecimiento de la población seguirá alentado por dos factores: la preferencia de las personas por mudarse de áreas rurales a zonas urbanas (que supera actualmente el $54 \%$ de la población urbana) y el crecimiento de la población urbana como tal. Estos dos factores combinados duplicarán la población urbana para 2050, de los cuales la tercera parte de esta población vivirá en condiciones de pobreza (UN, 2014; PNUD, 2014; United Nations Population Fund [UNFPA], 2011). 
Figura 1.

Tendencia del crecimiento poblacional mundial, urbano, rural y en condición de pobreza para los ańos 2010 y 2050

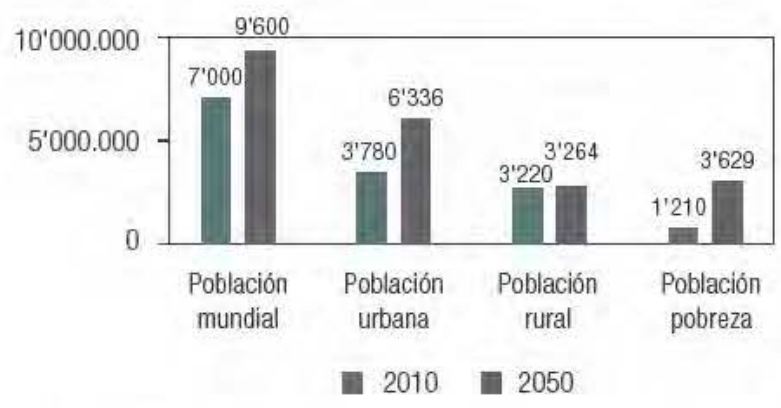

Fuente: elaboración propia con base en UN (2014) PNUD (2014) y UNFPA (2011)

Según Cities Biodiversity Outlook (CBD, 2012), existen cinco grandes tendencias en el proceso de urbanización que tienen repercusiones y problemáticas graves para la biodiversidad y los servicios ecosistémicos:

- Las superficies urbanas se expanden más rápido (triple) que las poblaciones urbanas (doble).

> La expansión urbana utilizará en gran medida los recursos naturales a escala mundial.

- Gran parte de la expansión urbana se producirá en regiones con baja capacidad económica, es decir, principalmente en países en vías de desarrollo.
, El crecimiento urbano se está dando rápidamente en zonas adyacentes ricas en biodiversidad.

El ritmo de la urbanización es más alto en regiones donde no existe capacidad para formular políticas y la gobernanza no cuenta con recursos económicos ni recursos humanos capacitados.

Más del $80 \%$ de la población de América Latina vive en ciudades y se prevé que para 2050 alcance el $90 \%$, y se convierte en la región más urbanizada del mundo (UN, 2014). A medida que la población y las economías de América Latina crecen, las demandas por recursos naturales para la calidad de vida de sus habitantes aumen$\tan$ (ver Figura 2).

En 1995 los 25 hotspot de biodiversidad eran el hogar de 1,1 millones de personas, o el 19\% de su población humana (Cincotta, Wisnewski y Engelman, 2000). Entre 1995 y 2000, la tasa de crecimiento anual estimada para los hotspot fue $38 \%$, mayor que la tasa global. Por lo tanto, estos hotspot no solo son el hogar de casi una quinta parte de la población mundial, sino también los más poblados y los de un crecimiento más rápido que el resto del mundo (Williams, 2012).
Figura 2.

Hoy en dia, las regiones más urbanizadas incluyen Norteamérica $(81 \%)$, América Latina y el Caribe ( $80 \%)$, Europa (73\%). En contraste, Africa y Asia siguen siendo rurales, con un $40 \%$ y $47 \%$ de sus respectivas poblaciones urbanas. En total, el $54 \%$ de la población mundial vive en zonas urbanas

Fuente: elaboración propia con base en datos de UN-DESA (2014)

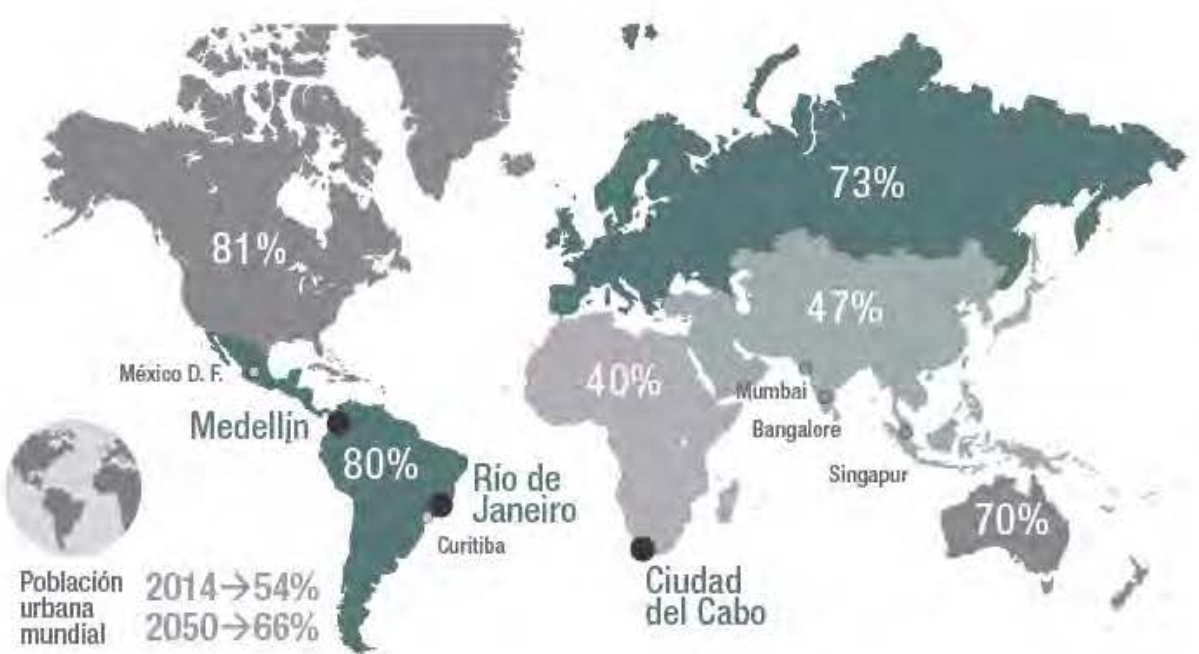




\section{Presiones urbanas sobre la biodiversidad}

Cada vez hay más evidencias de que las actividades humanas están afectando el funcionamiento de la Tierra a un grado que amenaza la resiliencia del sistema (Steffen, Richardson, Rockström, Cornell, Fetzer, Bennett y Sörlin, 2015). La tendencia del crecimiento poblacional podría desestabilizar los sistemas biofísicos críticos y desencadenar cambios ambientales bruscos o irreversibles que serían perjudiciales, o incluso catastróficos, para el bienestar humano (Rockström, Steffen, Noone, Persson, Chapin, Lambin, y Foley, 2009). Algunos resultados de las presiones son la pérdida y transformación del hábitat, las especies invasoras, la contaminación, los cambios de uso del suelo, la sobreexplotación de los recursos biológicos y el cambio climático global, todo a causa la disminución de la diversidad biológica (Johnson y Klemens, 2005; CBD, 2012), lo que genera una homogeneización del paisaje y, por lo tanto, la degradación de los servicios ecosistémicos necesarios para el bienestar humano. A su vez, la expansión urbana no planificada, o mal gestionada, conduce a la contaminación, a la degradación de los componentes de la biodiversidad y a patrones de producción y de consumo insostenibles (UN, 2014).

La presión sobre la biodiversidad es cada vez mayor, por lo cual su conservación depende de las normativas con que se rigen las ciudades, y de cómo respondan de acuerdo con la transformación del sistema urbano, para abarcar la integridad de los ecosistemas (Wilkinson, Sendstad, Parnell y Schewenius, 2013). Es por esto que la urbanización puede ser vista, en un escenario negativo, como la causa de la destrucción y la fragmentación de los hábitats nativos, en los que se crean otros hábitats que favorecen a especies no nativas y generalistas, que alteran y modifican los regímenes naturales. Esta situación se presenta con más severidad en contextos de barrios marginales. Además, es alarmante que los países en vías de desarrollo, que poseen la mayor biodiversidad, a la vez, tengan un alto desconocimiento de ella.

\section{Crecimiento informal y pobreza}

La pobreza es cada vez más un fenómeno urbano, y esto plantea una problemática crítica para la biodiversidad urbana y la planeación territorial, ya que el urbanismo informal es una de las fuerzas dominantes de crecimiento urbano en los países en desarrollo (UN-Habitat, 2014), que no reconoce el valor ecológico del entorno y presenta altos índices de pobreza, vulnerabilidad y necesidades básicas insatisfechas. Los habitantes en asentamientos precarios ya constituyen alrededor del $32 \%$ de la población urbana en las regiones en desarrollo del mundo, una tendencia que configurará el crecimiento urbano a partir de la formación de nuevos barrios marginales (UN-Habitat, 2013). Eso significa que más del $15 \%$ de la población del mundo sigue siendo vulnerable a la pobreza multidimensional (UN, 2014). Durante el último medio siglo, una serie de intervenciones han tratado de mejorar las condiciones de vida en estos barrios informales, como parte de su compromiso por erradicar la pobreza extrema y el hambre, que forma parte de los Objetivos de Desarrollo del Milenio (PNUD, 2014 y Williams, 2012). Sin embargo, sigue existiendo una falta de estrategias viables para responder a las necesidades de los 2.000 millones de habitantes de barrios informales adicionales, que se espera para el año 2050 (Werthmann, 2011).

Muchos de los asentamientos precarios han evolucionado hasta incorporarse a la ciudad convencional. Esto ha ocurrido con los barrios mejor localizados desde el punto de vista urbano (cercanía al centro de la ciudad, a los medios de transporte público y ubicación segura) y que tienen mayor tiempo de existencia. Por el contrario, los 
asentamientos de formación reciente, se ubican en áreas de difíciles condiciones urbanísticas, ambientales y de accesibilidad, debido a la escasez de suelos aptos para la urbanización y a recursos financieros para poder acceder a otras alternativas (Centro de Estudios Urbanos y Ambientales [Urbam], 2013).

\section{Desconocimiento de los servicios de los ecosistemas}

Las ciudades dependen de los ecosistemas, dentro y fuera del entorno urbano, para una amplia variedad de bienes y servicios que son esenciales para la sostenibilidad económica, social, ambiental y cultural (CBD, 2012). Sin embargo, la falta de información, comprensión y planificación de los efectos de las decisiones sobre el territorio, puede conducir a la pérdida de estos servicios esenciales. Desde un punto de vista económico, esto significa que el uso subóptimo de este 'capital natural', resulta en pérdidas innecesarias de bienestar y calidad de vida, disminución en los presupuestos de la ciudad y en las oportunidades de las economías locales (The Economics of Ecosystems and Biodiversity [TEEB], 2011). Además, un tema poco estudiado y de gran importancia es la biología de las especies en ecosistemas urbanos y periurbanos. Este interés por evaluar los impactos de la urbanización en la diversidad, abundancia y función de estas especies es reciente (Alcaldía de Medellín et al., 2014), al igual que el desarrollo de la ecología urbana, como ciencia necesariamente interdisciplinaria, y el reconocimiento de las ciudades como manifestaciones de la ecología humana (Soares et al., Essy, Sanz, da Silva, Albertin y Santos, 2015).

Según la Evaluación de los Ecosistemas del Milenio, el $60 \%$ de los servicios de los ecosistemas son degradados o usados de manera no sostenible, lo cual tiene efectos adversos sobre el bienestar humano (Millenium Ecosystem Assessment
[MEA], 2005), por lo que la protección y el uso sostenible de los ecosistemas ya no son un interés aislado, sino un componente clave del desarrollo sostenible global. La rápida degradación de la capacidad de los ecosistemas para generar servicios exige una mejor comprensión de cómo mantener las funciones del ecosistema, y requiere ampliar este conocimiento a contextos institucionales y de gobernanza. Por esa razón, los ecosistemas deben tenerse en cuenta en la planificación, la gestión y los presupuestos de las ciudades para delinear los costos y beneficios de las diferentes políticas y, de esta manera, tomar decisiones mejor informadas (TEEB, 2011).

\section{Planeación urbana limitada}

La expansión urbana tiene un ritmo mucho más acelerado en contextos en los que la capacidad para formular políticas es nula y donde la gobernanza urbana suele no contar ni con recursos económicos ni con recursos humanos capacitados (CBD, 2012). Este hecho conduce a una planeación limitada frente a un territorio lleno de complejidades, en donde las soluciones son sesgadas y no reconocen aspectos relevantes como la conservación de la biodiversidad o el crecimiento de los asentamientos informales. Por otra parte, no reconocen las complejas interacciones entre el patrón urbano y los procesos ecológicos que se producen en múltiples escalas. Para entender cómo las poblaciones de especies, y las características de una comunidad, cambian en respuesta al desarrollo urbano, se debe ampliar el conocimiento acerca de las razones y los efectos de la estructura del ecosistema y sus funciones en el paisaje urbano (Alberti, 2005).

Elander y otros autores (2005) hacen un estudio en algunas ciudades suecas sobre la importancia de integrar la biodiversidad a la planificación urbana, y algunos hallazgos evidencian que los planes de las ciudades se centran habitualmente en 
aspectos muy generales de la biodiversidad, que son difíciles de implementar a escala local. Además, existe una mala comprensión de la biodiversidad pues se refieren más a estructuras verdes y aspectos culturales asociados a la recreación, y no al proceso ecológico que implica, ni a sus interacciones en diferentes escalas.

\section{Motivaciones para conservar la biodiversidad en las ciudades}

En los ecosistemas urbanos dominados por el hombre, la conservación de la biodiversidad puede ser un asunto controversial (Dearborn y Kark, 2010); la razón se debe a que existen diferentes percepciones, definiciones, mediciones y valoraciones acerca de la biodiversidad que llevan a la conservación. Además, al saber que la intención no es restaurar las zonas urbanizadas de nuevo a un estado natural y prístino, el obtro de las ciudades tiene múltiples motivaciones (Faeth, Bang y Saari, 2011). Según Dearborn y Kark (2010) estas podrían estar relacionadas con la preservación de la biodiversidad local, la creación de pasos intermedios hacia hábitats no urbanos, la comprensión y facilitación de respuestas al cambio ambiental, el mejorar la educación ambiental, el proporcionar servicios del ecosistema, el cumplir con responsabilidades éticas y el mejorar el bienestar humano. Razones que complementan los enfoques ecológicos, económicos, culturales, sociales, políticos y del cambio climático, que nos darán un punto de partida para entender la integralidad de la biodiversidad urbana, como lo veremos más adelante.

\section{Biodiversidad urbana y procesos ecológicos}

diversidad funcional y mejora la estabilidad ecológica al influir en la resiliencia y la resistencia a los cambios ambientales y, por lo tanto, es crucial para la calidad de vida en general. En este contexto, los espacios urbanos verdes lentamente han sido reconocidos como hábitats locales importantes en las ciudades (Chapin, Zavaleta, Eviner, Naylor, Vitousek, Reynolds, Mack, 2000; Barrico, Azul, Morais, Coutinho, Freitas y Castro, 2012).

El paisaje urbano muestra algunos patrones interesantes con respecto a la diversidad de plantas y animales (CBD, 2012):

- El número de especies de plantas de las zonas urbanas a menudo se correlaciona con el tamaño de la población humana, más aún de lo que hace con el tamaño de la zona de la ciudad.

- La edad de la ciudad afecta la riqueza de especies; las grandes ciudades, de mayor edad, tienen más especies de plantas que las grandes ciudades, más jóvenes.

La biodiversidad es un componente importante de cualquier sistema ecológico, que promueve la
- La diversidad se puede correlacionar con la riqueza económica.

- El 20\% de las especies de aves del mundo y el $5 \%$ de las especies de plantas vasculares se producen en las ciudades.

- En promedio, el 70\% de las especies de plantas y el $94 \%$ de las especies de aves que se encuentran en las zonas urbanas son nativas de la región circundante.

La importancia y la singularidad de la biodiversidad urbana se deriva de sus características especiales (Müller et al., 2010): las condiciones físicas y ecológicas exclusivas de las ciudades; el mosaico mezclado y hábitat a pequeña escala; la combinación de especies autóctonas e introducidas que crean un hábitat recombinante con su propia dinámica ecológica; y la presencia de tipos de 
hábitats y comunidades biológicas que son significativamente diferentes de otros que ocurren en otras partes (Lugo, 2014).

De los diez países con mayor biodiversidad mundial, cinco están en América Latina: Brasil, Colombia, Ecuador, México y Perú, que también comparten la cordillera de los Andes, que es la zona con mayor biodiversidad del mundo. En América Latina viven alrededor del $27 \%$ de los mamíferos del mundo, así como también el 34\% de su vegetación, $37 \%$ de sus reptiles, $47 \%$ de sus aves y el $47 \%$ de sus anfibios (UN-Habitat, 2010).

\section{Servicios de los ecosistemas}

y bienestar humano

Los ecosistemas ofrecen innumerables beneficios para el sustento del desarrollo social y económico, así como para la mitigación del cambio climático (Elmqvist, Fragkias, Goodness, Güneralp, Marcotullio, McDonald y Wilkinson, 2013; Gómez-Baggethun y Barton, 2013). Al tener en cuenta los servicios de los ecosistemas, las ciudades tienen la oportunidad de hacer algunos cambios muy positivos: el ahorro en los costos municipales, el impulso a las economías locales, la mejora de la calidad de vida y el asegurar los medios de vida a su población. En este contexto, las áreas urbanas verdes son una parte vital del paisaje, dado que proporcionan contacto con la vida silvestre, lo cual trae beneficios socioecológicos adicionales a la calidad de vida (Barrico et al., 2012 y Rincón-Ruíz, Echeverry-Duque, Piñeros, Tapia, David, Arias-Arévalo y Zuluaga, 2014).

Los servicios de los ecosistemas urbanos se han clasificado de varias formas, pero para esta revisión nos guiaremos en las cuatro categorías descritas por Haase y colaboradores (MEA, 2005; Cowling, Egoh, Knight, O'Farrell, Reyers, Rouget y Wilhelm-Rechman, 2008; TEEB 2011;
Haase, Larondelle, Andersson, Artmann, Borgström, Breuste y Kabisch, 2014):

1 Servicios de aprovisionamiento que incluyen salidas de material de los ecosistemas, incluidos los alimentos, el agua, las plantas medicinales y otros recursos.

, Servicios de regulación que mantienen funciones tales como la calidad del aire y del suelo, las inundaciones, el agua de lluvia y el control de enfermedades.

, Servicios de hábitat y de apoyo que proporcionan espacios de vida para los organismos, y mantienen la diversidad vegetal y animal.

- Servicios culturales que incluyen beneficios socioecológicos, psicológicos y cognitivos como la recreación, la estética y el turismo (TEEB, 2011).

Las comunidades humanas menos favorecidas, como lo plantean los Millenium Ecosystem Assesment (MEA, 2005) y el TEEB (2010), son generalmente las más afectadas por la transformación de los ecosistemas. Debido a su dependencia inmediata y las problemáticas asociadas con la pobreza y la desigualdad, hacen que se dé una tendencia a la existencia de conflictos socioambientales.

Mediante la identificación y la comprensión del valor de estos beneficios, los planificadores, educadores, ciudadanos, gestores y demás tomadores de decisión, pueden avanzar hacia la creación de una ciudad sostenible. A largo plazo, el mantenimiento de los ecosistemas es la solución más rentable para satisfacer las necesidades humanas, en especial si estos servicios son de carácter insustituible.

\section{Planeación urbana y gestión integral}

Las ciudades tienen un papel clave en el suministro de servicios, la construcción y disposición 
de establecimientos, en enfrentarse a las desigualdades y en gestionar el medio ambiente como aporte a la salud humana. Estas están ubicadas en ambientes clave próximas a ríos, estuarios, manglares y bosques, entre otros. Por lo tanto, estas suelen desarrollarse en escenarios cruciales para la conservación biológica, hecho que pone de manifiesto la importancia de la planificación de urbes al considerar la vida silvestre (Soares, 2012). El ideal de esta planificación es que contenga herramientas que integren beneficios mutuos: como la salud de los seres humanos y la de la biodiversidad (CBD, 2012), por lo que existen grandes oportunidades para facilitar los patrones de crecimiento sostenible, así como la gestión de la biodiversidad y los servicios del ecosistema (Alberti, 2005).

Según Elander y otros autores (2005), la estructura física del paisaje urbano se puede dividir en cuatro categorías: 1) edificios, 2) calles, 3) plazas, estructura técnica (como el suministro de electricidad, agua o sistemas de alcantarillado) y 4) la estructura verde. Esta última se define como todas las tierras blandas (no duras) y sin desarrollar. La estructura verde es multifuncional, pues como hemos visto va de lo social a las funciones ecológicas. En relación con la biodiversidad, la estructura verde puede aumentar en el paisaje urbano la conectividad entre hábitats en diferentes escalas biológicas, aunque esta se caracteriza por los hábitats residuales en etapas tempranas sucesivas, la invasión de especies exóticas y las zonas verdes aisladas (Niemelä, 1999 y Elander et al., 2005).

Las ciudades tienen una gran responsabilidad en cuanto a mejorar las condiciones de los asentamientos informales, al igual que con la planificación y con la gestión urbana orientada a la disminución de los impactos ambientales (Niemelä, 1999 y; Soares et al., Santos, Sanz, Sanz y Albertín, 2016). Algunas estrategias y herramientas parciales que hace UN-Habitat (2014) son: mejorar las condiciones actuales de los barrios, proporcionar vivienda asequible y adecuada, contar con una regulación jurídica acorde a las necesidades, racionalizar el espacio urbano para el crecimiento futuro y prevenir la formación de barrios marginales. A estrategias como estas, hay que sumarles las consideraciones desde la biodiversidad como crear empleos verdes, garantizar la capacidad de recuperación ante el cambio climático o, servicios públicos asequibles, entre otros (Iclei, 2010).

En materia local, Colombia ya tiene algunos avances en generación de política pública integral como la Política Nacional para la Gestión de la Biodiversidad y los Servicios de los Ecosistemas (Política Nacional para la Gestión Integral de la Biodiversidad y los Servicios Ecosistémicos [PNGIBSE], 2012), y que fue el punto de referencia para construir una política pública en biodiversidad y servicios ecosistémicos locales para Medellín, como ejercicio pionero en la implementación de esta política nacional (Alcaldía de Medellín et al., 2014) o la Política Pública de Ecourbanismo y Construcción Sostenible para Bogotá (Alcaldía Mayor de Bogotá, D. C. et al., 2014).

\section{Enfoques de la biodiversidad urbana}

La biodiversidad, y las funciones y servicios que de ella se derivan, constituyen una dimensión dinámica de la realidad planetaria. Por tanto, hablar de su conservación o uso sostenible requiere de un enfoque adaptativo basado en el aprendizaje social. Entender la biodiversidad como componente fundamental de los sistemas socioecológicos, cuya dinámica atraviesa por diferentes fases o ciclos adaptativos, obliga a fortalecer un enfoque de trabajo integrado de diferentes perspectivas (Rincón-Ruíz et al., 2014). 
Además de los procesos biológicos, la biodiversidad urbana es una evidencia de la transformación histórica del territorio, establecida tanto por aspectos sociales y culturales, tales como el comportamiento y las percepciones, como por las condiciones geográficas, económicas y políticas, que al conceptualizarlas e implementarlas dentro del ordenamiento del territorio, dibujan el paisaje en múltiples escalas, tiempos y actores (Ignatieva, 2010 y Müller $e t$ al., 2010). En cuanto a la literatura de la biodiversidad urbana, se define el concepto teniendo en cuenta el grado de intervención humana y la escala espacial, y se resalta la importancia de la biodiversidad en el contexto urbano, así como su influencia y conexión multiescalar (Nowak, 2010; Arellano y Halffter, 2003 y CBD, 2012). Lo anterior se traduce a una biodiversidad que trasciende las escalas global (hotspot de biodiversidad), nacional
(Parques Nacionales Naturales), regional (áreas protegidas), de áreas periurbanas (parques naturales públicos), local (retiros de quebradas, cerros), barrial (antejardines, separadores viales) y sub-barrial (terrazas y balcones verdes).

Para esto es necesario tener una perspectiva integrada de lo que implica la biodiversidad urbana vista desde varios enfoques (ver Tabla 1), así como se muestra en las contribuciones que se consolidaron en "La Declaración de Erfurt" en 2008, en donde claramente existe un abanico de enfoques necesarios para entender la importancia y la función de la biodiversidad urbana, y de llevar esto a la práctica local (Müller $e t$ al., 2010). Los enfoques son los siguientes: investigación y evaluación de la biodiversidad en zonas urbanas; aspectos culturales y sociales; cambio climático; y diseño y planificación de la biodiversidad urbana.

Tabla 1.

Definición de los enfoques de biodiversidad urbana

\begin{tabular}{|c|c|c|}
\hline Enfoques & Definición de los enfoques de biodiversidad urbana & Referencia \\
\hline 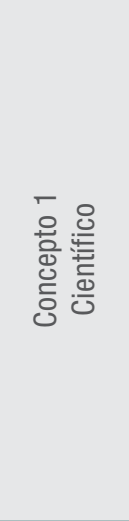 & $\begin{array}{l}\text { Desde la visión clásica de la biología, la biodiversidad urbana puede ser descrita en } \\
\text { términos de riqueza, abundancia, composición y distribución espacial de las especies } \\
\text { y las interacciones entre sus componentes, en hábitats controlados o condicionados } \\
\text { por las sociedades humanas. También es vista como el componente de cualquier } \\
\text { sistema ecológico que promueve la diversidad funcional y mejora la estabilidad } \\
\text { ecológica al influir en la resiliencia y la resistencia a los cambios ambientales. } \\
\text { El reconocimiento de los patrones espaciales y temporales de la biodiversidad por medio de la } \\
\text { cantidad de especies que utiliza un mismo hábitat o recurso (diversidad alfa), o la respuesta } \\
\text { de los organismos a la heterogeneidad del espacio (diversidad beta), están determinadas } \\
\text { por los procesos históricos y geográficos que actúan en lo regional (diversidad gamma). }\end{array}$ & $\begin{array}{c}\text { Andrade y Wills (2010) } \\
\text { Martín-López, González, } \\
\text { Díaz, Castro y García- } \\
\text { Llorente (2007) } \\
\text { Arellano y Halffter (2003) } \\
\text { Salas y Ortega (2005) } \\
\text { Hooper, Chapin, Ewel, } \\
\text { Hector, Inchausti, Lavorel } \\
\text { y Schmid (2005) } \\
\text { Chapin et al., (2000) } \\
\text { Barrico et al., (2012) }\end{array}$ \\
\hline 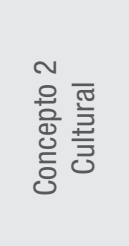 & $\begin{array}{l}\text { Las oportunidades que la ciudad ofrece para la biodiversidad dependen mucho } \\
\text { más del valor percibido por las personas por razones culturales, recreativas, de } \\
\text { amenidad, de identidad de lugar o de salud física y mental. Es por esto que el } \\
\text { desarrollo cultural de la humanidad influencia la biodiversidad urbana. A su vez, es } \\
\text { el primer y principal contacto de la población mundial con la naturaleza, y es clave } \\
\text { en la conformación cultural de las percepciones y actitudes de los ciudadanos. }\end{array}$ & $\begin{array}{c}\text { Millard (2010) } \\
\text { Shwartz, Turbé, Simon } \\
\text { y Julliard (2014) } \\
\text { Voigt y Wurster (2015) }\end{array}$ \\
\hline
\end{tabular}




\begin{tabular}{|c|c|c|}
\hline 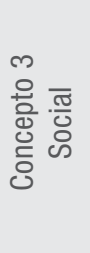 & $\begin{array}{l}\text { Las prestaciones sociales clave de la conservación de la biodiversidad urbana } \\
\text { son la calidad de vida y el bienestar humano en términos de seguridad, material } \\
\text { básico para la buena vida, la salud personal y comunitaria, las buenas relaciones } \\
\text { sociales y la libertad de elección y de acción. La biodiversidad puede actuar como } \\
\text { un agente para volver a conectar a los ciudadanos con su entorno de vida y con la } \\
\text { creación de conciencia de su responsabilidad social hacia la conservación. }\end{array}$ & $\begin{array}{l}\text { MEA (2005) } \\
\text { Cilliers (2010) } \\
\text { Kinzig, Warren, Martin, } \\
\text { Hope y Katti (2005) }\end{array}$ \\
\hline 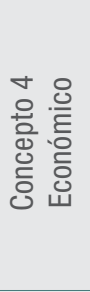 & $\begin{array}{l}\text { El valor que se le adjudica a la biodiversidad está referido a la importancia en cuanto } \\
\text { a sus funciones ecosistémicas. Este valor intrínseco de los procesos naturales se pone } \\
\text { en juego en la sociedad al asumir el costo en que se incurriría si no existieran, y por lo } \\
\text { tanto, en los recursos que se podrían dedicar a la creación de su ideal ecológico. }\end{array}$ & $\begin{array}{l}\text { Kinzig et al., (2005) } \\
\text { Dearborn y Kark (2010) } \\
\text { Azqueta, Alviar, Domínguez } \\
\text { y O'ryan, (2007) } \\
\text { Cilliers (2010) } \\
\text { Pearce (2007) }\end{array}$ \\
\hline 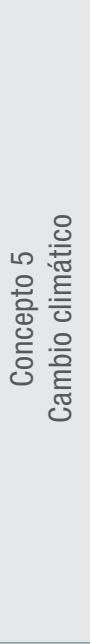 & $\begin{array}{l}\text { El clima local, los suelos, los procesos urbanos, la dispersión de semillas y la distribución } \\
\text { espacial de la vegetación se combinan, junto con el cambio climático, para producir } \\
\text { la diversidad biológica de las ciudades. La biodiversidad urbana promueve estabilidad } \\
\text { ecológica al influir en la resiliencia y la resistencia a los cambios ambientales. }\end{array}$ & $\begin{array}{c}\text { Nowak (2010) } \\
\text { Wilby y Perry (2006) } \\
\text { De Olivera, Balaban, } \\
\text { Doll, Moreno-Peñaranda, } \\
\text { Gasparatos, lossifova } \\
\text { y Suwa (2011) } \\
\text { Thomas, Cameron, Green, } \\
\text { Bakkenes, Beaumont, } \\
\text { Collingham, Hughes (2004) } \\
\text { Walther, Post, Convey, } \\
\text { Menzel, Parmesan, Beebee } \\
\text { y Bairlein (2002) } \\
\text { McCarty (2001) } \\
\text { Barrico et al., (2012) }\end{array}$ \\
\hline 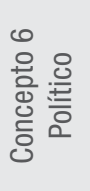 & $\begin{array}{l}\text { El manejo ideal de la biodiversidad ocurre por medio de la interfaz ciencia y política, } \\
\text { es decir, por medio de la relación directa del conocimiento y la toma de decisiones. } \\
\text { Para esto es necesario la investigación sobre el territorio, sus umbrales de cambio } \\
\text { y los riesgos derivados de estos para, de esta forma, fortalecer la gobernanza. }\end{array}$ & $\begin{array}{l}\text { Andrade y Wills (2010) } \\
\text { Bello, Báez, Gómez, } \\
\text { Orrego, Nägele (2014) } \\
\text { Doornbos (2001) }\end{array}$ \\
\hline 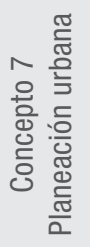 & $\begin{array}{l}\text { El futuro de los paisajes biodiversos depende directamente de un enfoque integrado, en la } \\
\text { cooperación de diferentes actores y la educación en los diferentes niveles. Sin embargo, } \\
\text { los enfoques y prácticas de planificación urbana actuales, generalmente carecen de los } \\
\text { conocimientos ecológicos y la comprensión de sus impactos y consecuencias. Los gobiernos } \\
\text { municipales pueden beneficiarse de un enfoque integrado de planificación urbana con una } \\
\text { comprensión ecológica para abordar los problemas relacionados con la biodiversidad. }\end{array}$ & $\begin{array}{l}\text { Niemelä (1999) } \\
\text { Ignatieva (2010) } \\
\text { CDB (2012) }\end{array}$ \\
\hline 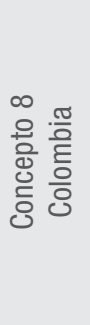 & $\begin{array}{l}\text { Teniendo en cuenta el contexto colombiano, se debe considerar que hay varios aspectos } \\
\text { claves para los ejercicios de valoración como herramienta para la gestión del territorio. } \\
\text { Para asegurar una toma de decisiones más equilibrada es fundamental reconocer } \\
\text { todos los valores asociados con la biodiversidad y la necesidad urgente de decisiones } \\
\text { ajustadas a las dinámicas del cambio global, el auge de nuevas iniciativas para el } \\
\text { desarrollo de instrumentos económicos que sustenten la biodiversidad en la lógica del } \\
\text { mercado, y el creciente número de controversias y debates que sitúan a la sociedad } \\
\text { en disputas sobre el uso del territorio y los modelos de desarrollo económico. }\end{array}$ & $\begin{array}{l}\text { Rincón-Ruiz (2014) } \\
\text { Christie, Fazey, Cooper, } \\
\text { Hyde, Kenter (2012) } \\
\text { Carrizosa (2006) } \\
\text { Sánchez, Díaz, } \\
\text { Formisano (2003) } \\
\text { TEEB (2010) }\end{array}$ \\
\hline
\end{tabular}

Fuente: elaboración propia con base en la revisión bibliográfica de biodiversidad urbana presentada en la columna de referencias 


\section{Enfoques de los servicios de los ecosistemas urbanos}

Adoptar un enfoque de servicios ecosistémicos permite a las ciudades dimensionar su dependencia sobre las áreas naturales de soporte, así como reconocer que la conservación de los ecosistemas urbanos incrementa el bienestar humano, reduce futuros costos asociados a la gestión del riesgo, activa las economías locales y permite identificar oportunidades o trade-offs entre las propuestas de planeación, las políticas formuladas y las decisiones de infraestructura (TEEB, 2011).

Evidencia de la relevancia de algunos servicios ecosistémicos en la ciudad son (Haase et al., 2014):

, La reducción local de la contaminación atmosférica (Gómez-Baggethun et al., 2013)

, Las reducciones en el efecto isla de calor urbano (Schwarz, Lautenbach y Seppelt 2011)

, Los beneficios directos para la salud, tales como la menor prevalencia de asma infantil temprana (Lovasi, Quinn, Neckerman, Perzanowski y Rundle, 2008), reducción de la mortalidad, y mejoras generales de salud (Maas, Verheij, Groenewegen, Vries y Spreeuwenberg, 2006; Mitchell y Popham, 2008)

> Conocimiento ecológico público mejorado y conciencia de los retos de la sostenibilidad.

Desde el concepto de biodiversidad, las funciones de los ecosistemas son entonces el intermedio entre los procesos de los ecosistemas y los servicios de los mismos (de Groot, 1992). Un esfuerzo sustancial de investigación en servicios de los ecosistemas se despliega en la actualidad en el orden nacional e internacional (ver Tabla 2). Sin embargo, sigue faltando un enfoque coherente e integrado para una aplicación práctica del concepto de funciones de los ecosistemas en la planificación, la gestión y la toma de decisiones (International Council for Science [ICSU], United Nations Educational, Scientific and Cultural Organization [Unesco], United Nations University [UNU], 2008). La comprensión de cómo funcionan los ecosistemas urbanos, cómo cambian, y lo que limita su rendimiento puede colaborar en la comprensión general de los cambios en los ecosistemas y la gobernanza en un mundo que es cada vez más humano (Elmqvist, Alfsen y Colding, 2008; Haase et al., 2014).

Tabla 2.

Definición de los enfoques de servicios ecosistémicos urbanos

\begin{tabular}{|c|c|c|}
\hline Enfoques & Definición de los enfoques de servicios ecosistémicos urbanos & Referencia \\
\hline 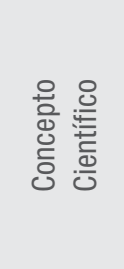 & $\begin{array}{l}\text { Servicios ecosistémicos son el subconjunto de funciones ecológicas (físicas, químicas } \\
\text { y biológicas) que son directamente relevantes para el bienestar humano. Ejemplos de } \\
\text { funciones de los ecosistemas incluyen la provisión de hábitat para la vida silvestre, el ciclo } \\
\text { del carbono, la descomposición, la productividad primaria y el ciclo de nutrientes. }\end{array}$ & $\begin{array}{l}\text { Haase et al., (2014) } \\
\text { Kremen (2005) } \\
\text { de Groot, Wilson y } \\
\text { Boumans (2002) } \\
\text { de Groot, Alkemade, } \\
\text { Braat, Hein y } \\
\text { Willemen (2010) }\end{array}$ \\
\hline 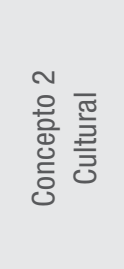 & $\begin{array}{l}\text { Los servicios culturales incluyen beneficios socioecológicos y no materiales (además de } \\
\text { psicológicos, cognitivos, simbólicos e intelectuales) que las personas obtienen del contacto } \\
\text { con sus alrededores, tales como recreación, estética, turismo, valores de lugar, el sentido de } \\
\text { comunidad y la identidad, la salud física y mental, la cohesión social y los valores educativos. }\end{array}$ & $\begin{array}{c}\text { Haase et al., (2014) } \\
\text { TEEB (2011) } \\
\text { Haines-Young y } \\
\text { Potschin (2013) } \\
\text { Chiesura (2004) } \\
\text { Chan, Satterfield y } \\
\text { Goldstein (2012) }\end{array}$ \\
\hline
\end{tabular}




\begin{tabular}{|c|c|c|}
\hline 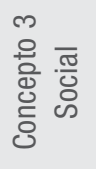 & $\begin{array}{l}\text { Las zonas urbanas proporcionan una serie de beneficios para mantener y mejorar la vida humana y } \\
\text { la calidad de vida con los servicios de los ecosistemas urbanos. Los servicios de aprovisionamiento } \\
\text { incluyen las salidas de material de los ecosistemas, incluidos los alimentos, el agua, las } \\
\text { plantas medicinales y otros recursos que contribuyen directamente al bienestar humano. }\end{array}$ & $\begin{array}{l}\text { TEEB } 2011 \\
\text { Gómez-Baggethun } \\
\quad \text { et al., (2013) } \\
\text { Haase et al., (2014) }\end{array}$ \\
\hline 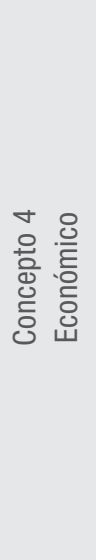 & $\begin{array}{l}\text { Recursos naturales vistos como medio de producción de bienes y servicios de los ecosistemas. } \\
\text { La pérdida de servicios de los ecosistemas en las zonas urbanas a menudo implica costos } \\
\text { económicos de una forma u otra. El uso subóptimo de este 'capital natural' resulta en pérdidas } \\
\text { innecesarias en el bienestar local, los presupuestos de la ciudad y las oportunidades de negocio. } \\
\text { Métodos como el costo evitado, por ejemplo, muestran la pérdida de la vegetación urbana } \\
\text { que conduce a mayores costos de energía en refrigeración en la temporada de verano. }\end{array}$ & $\begin{array}{c}\text { TEEB } 2010 \\
\text { Boyer y Polasky } \\
\text { (2004) } \\
\text { Tyrväinen, Pauleit, } \\
\text { Seeland y de } \\
\text { Vries (2005) } \\
\text { Escobedo, Kroeger } \\
\text { y Wagner (2011) } \\
\text { McPherson, Nowak, } \\
\text { Heisler, Grimmond, } \\
\text { Souch, Grant y } \\
\text { Rowntree (1997) } \\
\text { Chaparro y } \\
\text { Terradas (2009) } \\
\text { Daily y Ellison (2002) }\end{array}$ \\
\hline 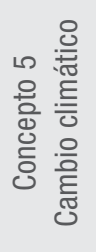 & $\begin{array}{l}\text { Con el aumento de la intensidad y frecuencia de los problemas ambientales que } \\
\text { afectan a las zonas urbanas, como consecuencia del cambio climático, los servicios } \\
\text { de los ecosistemas pueden cumplir un papel importante, y mantener altos niveles de } \\
\text { biodiversidad para el aumento de la resiliencia, la resistencia y la capacidad de adaptación } \\
\text { en las ciudades. La contribución de los servicios de los ecosistemas para aumentar la } \\
\text { resistencia a los choques se puede denominar como una forma de valor seguro. }\end{array}$ & $\begin{array}{c}\text { Kremen (2005) } \\
\text { Haase et al., (2014) } \\
\text { Meehl y Tebaldi } \\
\text { (2004) }\end{array}$ \\
\hline 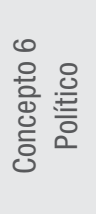 & $\begin{array}{l}\text { La investigación es crucial para adquirir conocimientos sobre los servicios de los ecosistemas } \\
\text { y desarrollar sus enfoques para la gestión integral. Sin embargo, los hallazgos deben ser } \\
\text { transferidos de manera efectiva, de la esfera científica a la formulación de políticas, para } \\
\text { mitigar la pérdida de biodiversidad y la degradación de los ecosistemas. La aplicación incluye la } \\
\text { sensibilización y la comunicación, la planificación estratégica y el desarrollo de herramientas. }\end{array}$ & $\begin{array}{l}\text { Haase et al., (2014) } \\
\text { Gómez-Baggethun } \\
\text { et al., (2013) }\end{array}$ \\
\hline 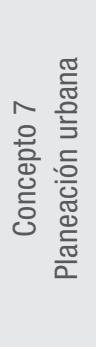 & $\begin{array}{l}\text { La planificación urbana puede servir como un instrumento eficaz para reducir los impactos } \\
\text { negativos de la urbanización sobre los servicios de los ecosistemas. Sin embargo, estos solo } \\
\text { pueden ser integrados a la política y la planificación después de comprender las relaciones } \\
\text { entre biodiversidad, procesos ecológicos y las funciones y servicios de los ecosistemas. } \\
\text { Debido al débil reconocimiento de los servicios de los ecosistemas en la política urbana } \\
\text { y la planificación en la mayoría de ciudades, se prioriza en el avance de } \\
\text { herramientas espaciales en combinación con el análisis multicriterio en la } \\
\text { evaluación y valoración de los servicios del ecosistema urbano. }\end{array}$ & $\begin{array}{l}\text { Gómez-Baggethun } \\
\text { et al., (2013) } \\
\quad \text { TEEB } \\
\quad(2011) \\
\text { Haase et al., (2014) }\end{array}$ \\
\hline 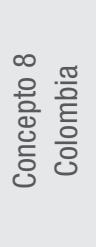 & $\begin{array}{l}\text { El contexto ambiental del país es heterogéneo (múltiples realidades en el territorio } \\
\text { por la diversidad de actores), dinámico (conflictos entre valores e intereses que cambian, } \\
\text { en algunos casos, transformándose en nuevas realidades), complejo (múltiples variables, } \\
\text { actores y relaciones entre estos) y conflictivo (relaciones conflictivas entre actores). } \\
\text { Este contexto exige un abordaje de la realidad desde la perspectiva de la complejidad } \\
\text { que reconozca las diferencias asociadas a múltiples lenguajes de valoración. }\end{array}$ & $\begin{array}{c}\text { Rincón-Ruiz (2014) } \\
\text { Carrizosa (2003) } \\
\text { Carrizosa (2014) } \\
\text { Martínez-Alier (2005) }\end{array}$ \\
\hline
\end{tabular}

Fuente: elaboración propia con base en la revisión bibliográfica de servicios ecosistémicos urbanos presentado en la columna de referencias 


\section{Análisis de ciudades}

Al tener una visión integral de los enfoques de la biodiversidad y los servicios ecosistémicos urbanos, claves para comprender la relación entre los habitantes de las ciudades y su entorno, aparece un escenario emergente de crecimiento informal en el cual domina la tendencia a la expansión urbana que vimos anteriormente. Si bien no todos los pobres urbanos residen necesariamente en tugurios (UN-Habitat, 2014), es claro que existe una correlación directa entre informalidad y pobreza, donde ambas terminan siendo causa y efecto la una de la otra. Por un lado, la informalidad urbana nace como una consecuencia de la falta de recursos de estos habitantes para acceder a la ciudad formal. Por el otro, como por pobreza se entiende también un bajo nivel de educación y de condiciones de salud, un hábitat degradado conlleva por sí solo a un empeoramiento de las condiciones de pobreza (UN-Habitat, 2013) y de su entorno físico.
Son recientes y pocas las investigaciones que articulan biodiversidad urbana con asentamientos informales (ver Figura 3). De igual forma, las alternativas de planeación existentes o propuestas en estos escenarios apenas están siendo consideradas. Por esta razón, se propone seleccionar tres ciudades que cumplan con las siguientes características:

, Ciudades con alta biodiversidad, con especies endémicas, y con iniciativas de los gobiernos por implementar políticas de biodiversidad urbana (ver Figura 4).

, Ciudades con altas dinámicas de migración de nuevos pobladores en asentamientos espontáneos, no consolidados, y en escenarios de alta vulnerabilidad (ver Figura 5).

, Ciudades donde el Gobierno haya propuesto múltiples estrategias para mejorar la calidad de vida y déficit de vivienda accesible y segura.

Figura 3.

Publicaciones de biodiversidad urbana y asentamientos informales por año

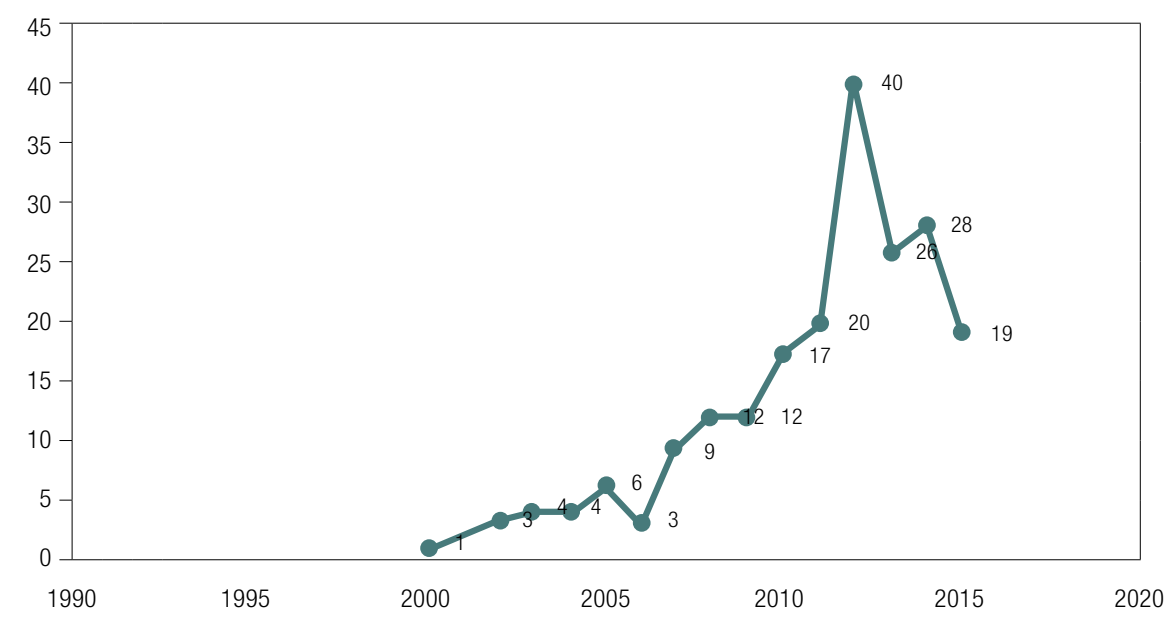

Fuente: elaboración propia con base en análisis bibliométrico en el metabuscador SCOPUS (2015) 
Figura 4.

Hotspot de Biodiversidad mundial, 1999

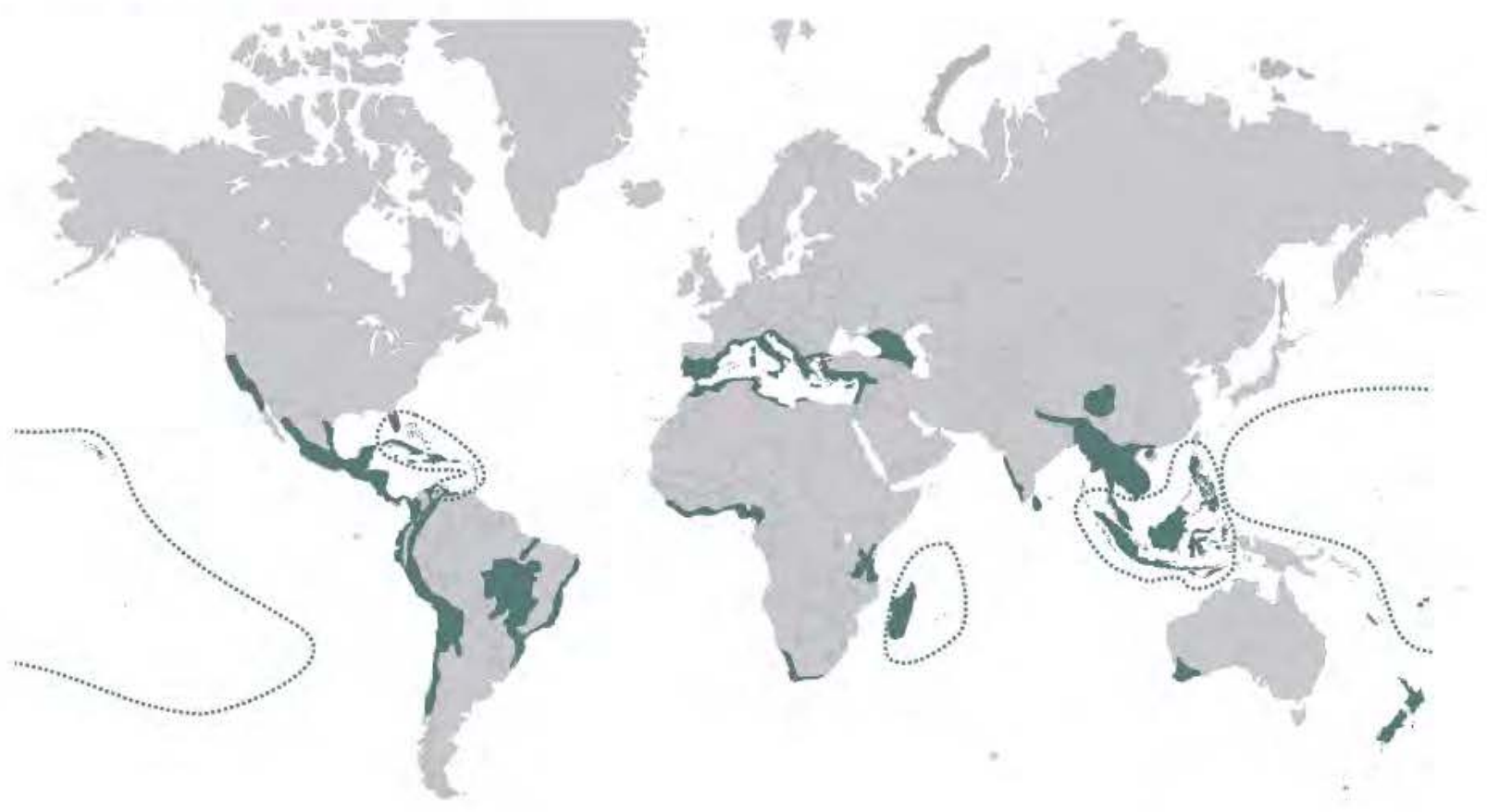

Fuente: elaboración propia con base en Conservation International Mittermeier, Myers, Mittermeier y Robles (1999)

Figura 5.

Población en asentamientos informales ubicadas en zonas urbanas por países, 2012

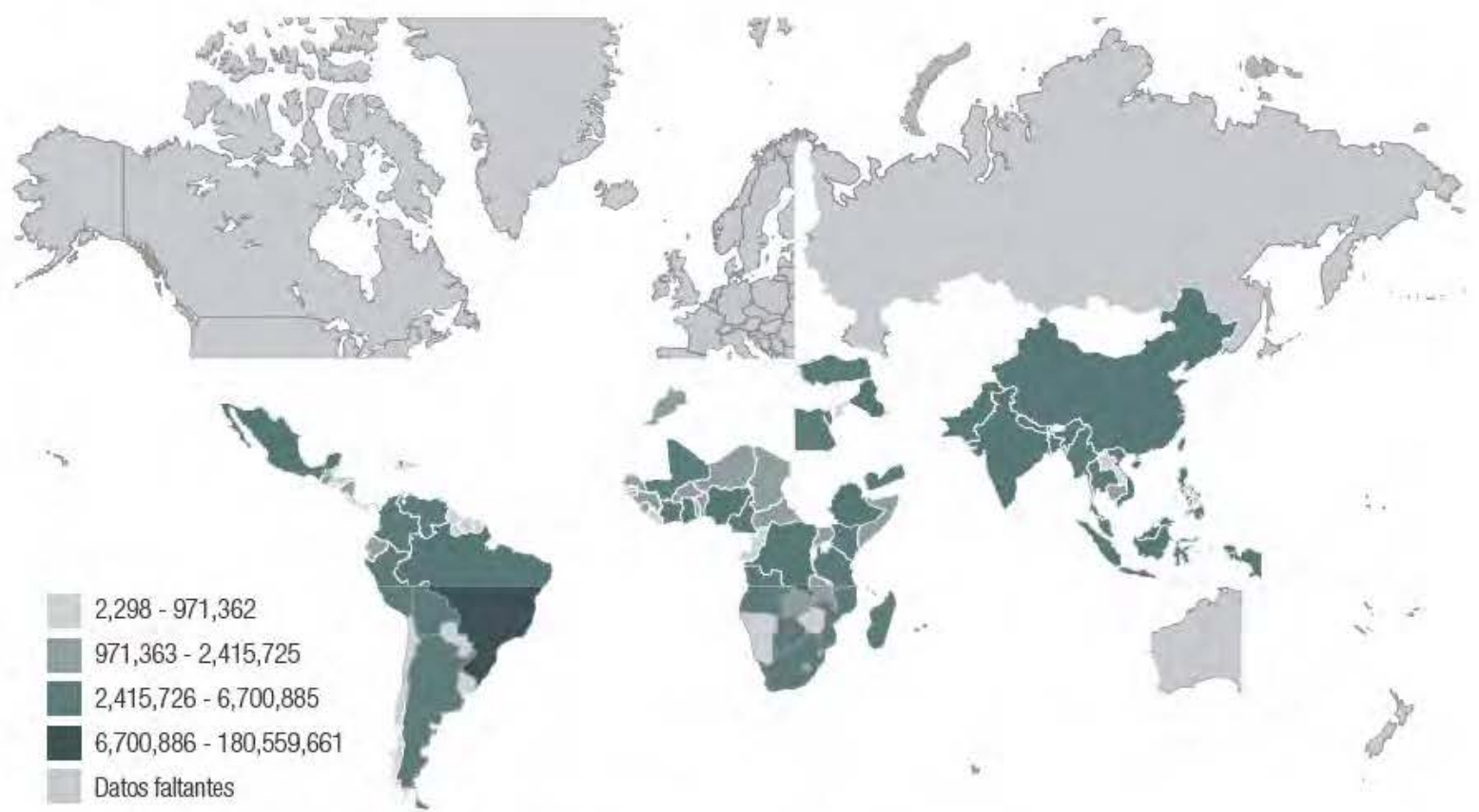

Fuente: elaboración propia con base en United Nations Statistics Division, Millennium Development Goals [UNSD] [MDG] (2012) 
A partir de estas características se seleccionaron las siguientes ciudades:

> Río de Janeiro: tiene la experiencia de haber sido sede del Convenio de Diversidad Biológica Río 92 y de Río +20. La ciudad está localizada en un ecosistema único llamado Mata Atlântica, que se caracteriza por biomas de elevada diversidad biológica, que contienen un amplio número de especies endémicas, $\mathrm{y}$ que se encuentran bajo extrema amenaza por factores como la urbanización y la agricultura, entre otros (Soares et al., 2016). Río posee los escenarios de crecimiento informal más impactantes, denominados favelas (ver Figura 7 , ciudad número 1 ).

- Ciudad del Cabo: es uno de los hotspots de biodiversidad en mayor estado de amenaza, y posee un nivel de migración de hasta 130 nuevos habitantes por día (Goldberg, Kula y Mhlalisi, 2009). Tiene varias experiencias y proyectos pilotos en biodiversidad, y es la sede del ICLEI-Gobiernos Locales por la Sostenibilidad (International Council for Local Enviromental Initiatives) que es una alianza global que aspira conciliar el desarrollo urbano con la conservación de los ecosistemas y el uso sostenible de los recursos naturales (ver Figura 8, ciudad número 2).

, Medellín: localizada en los Andes septentrionales es considerada como una ciudad con alta biodiversidad. Ya tiene una propuesta de Política de Gestión Integral de Biodiversidad y Servicios Ecosistémicos urbanos (Alcaldía de Medellín et al., 2014) y alberga escenarios de crecimiento informal en sus laderas (ver Figura 9 , ciudad número 3 ).

Estas fueron las tres principales ciudades en que se basó esta revisión (ver Figura 6) pero se agregan algunos casos relevantes de planeación en las ciudades de Bangalore, México D. F., Mumbai, Curitiba y Singapur (ver Figura 10). Los principales portales de información, y punto de partida para realizar los análisis de las ciudades fueron http://www, rio.rj.gov.br para Río de Janeiro; https://www.capetown.gov.za para Ciudad del Cabo; y para Medellín https://www.medellin. gov.co. Por su parte, los mapas son elaboración propia con base a la cartografía que cada municipalidad de la ciudad ofrece por medio de los portales mencionados.

Figura 6.

Hotspot de biodiversidad (1999) y población en asentamientos informales en zonas urbanas por paises (2009)

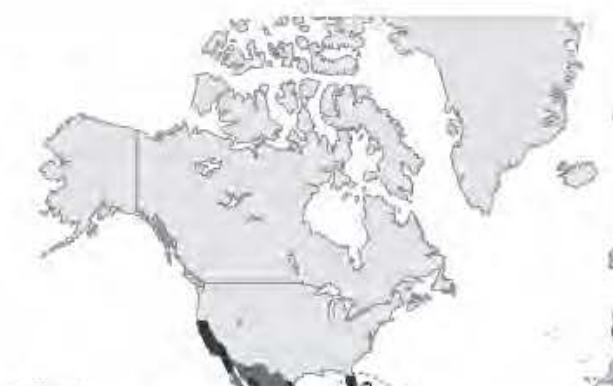

Hotspot de Biodiversidad

$2,298-971,362$

$971,363-2,415,725$

$2,415,726-6,700,885$

$6,700,886-180,559,661$

Datos faltantes

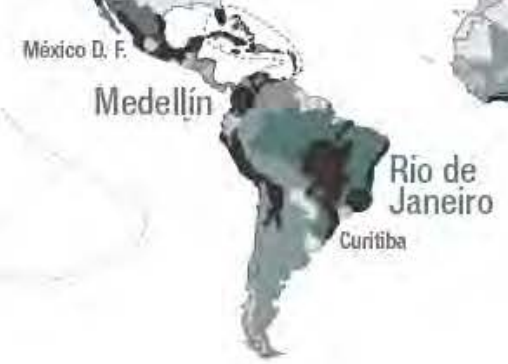

zio

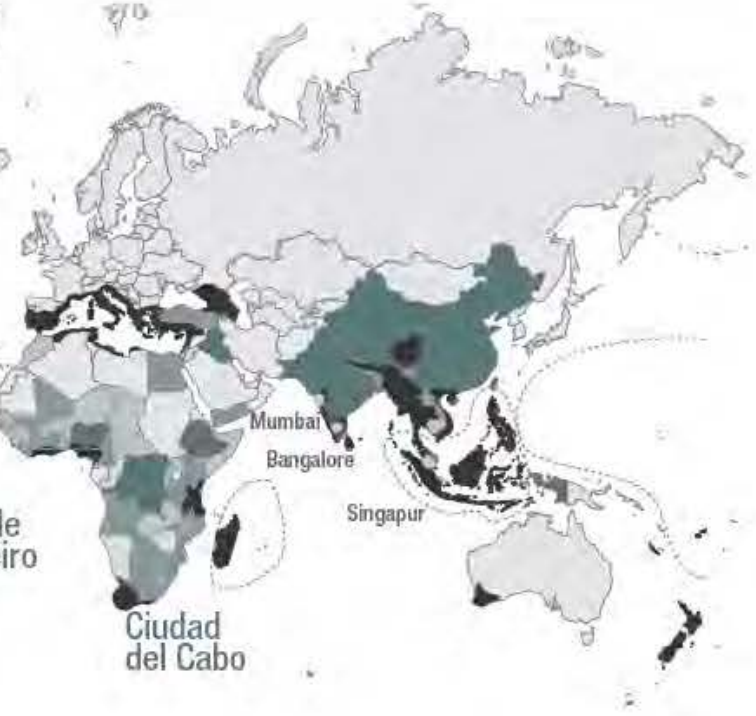


Figura 10.

Ficha de análisis de las ciudades de Río de Janeiro, Ciudad del Cabo, Medellin y algunos

referentes especificos de Bangalore, México D. F., Mumbai, Curitiba y Singapur

\section{RÍO DE JANEIRO}

ESTADO: Río de Janeiro - PAIS: Brasil

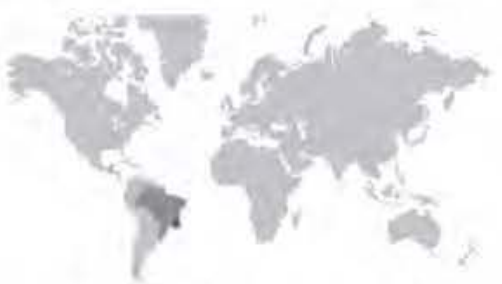

La ciudad de Rio de Janero se divide administrativamente por:

5 Áreas de Planificación (AP)

33 Regiones administrativas CAR]

16 regiones
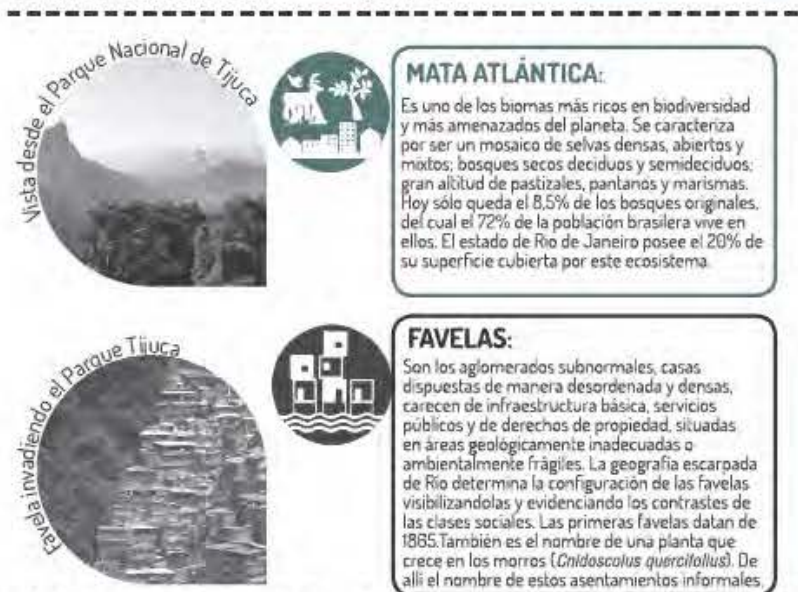

\section{FAVELAS:}

Son los agiomerados subnomales, casas dispuestas de manera desordenada y densars úblicos y de dererchos de propiectad situad en areas geologicamente inadecuadas o. ambientalmente frágiles La geografia escarpada de Rio determina la configuracion de las favelas visiblizandolas y evidenciando los contrastes de as clasel sociales Las primeras lavelas datan de 1865 . Tambien es el nambre de una planta que trece en los morros (Cnidoscoilus querciliollusis). De
alli el nambre de estos asentamientos informales.

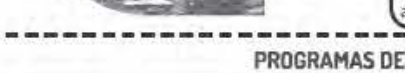

PROGRAMAS DE GOBIERNO Y AUTORIDADES AMBIENTALES

\section{SECRETARIA DE ESTADO DE AMGIENTE}

Promever besarrollo Sosternible intiegrado

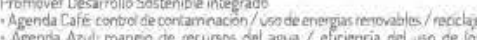

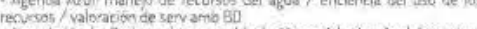

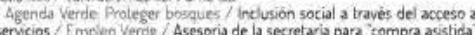

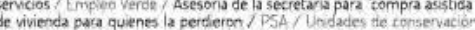
muncepal

\section{SECRETARIA DE ESTADO DE OBRAS}

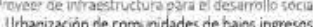

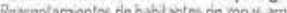
SECRETARIA DE ESTADOO DE VIVIENDA

Meorar el defiot de wivenda. "Mi cers mividd"

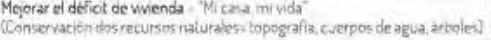

IPP. instituto Municipal de Urbanismo Pereira Passos CATALDSO OE PROGRAMAS DE INCLUSION

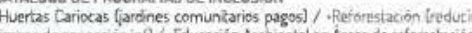

- Los Cuardanos te Plics (tormacion agentes amb?

- Gestion de la Tierra dialono rotidianc can las orranizaciones y los ideres de cada romunidad identificando necesidades y la creación de nuevos canales de participacion y calogo con el pobieme

- Gesbon de infortrucion e lnstutucional

PACTO DO RIO- inlegracion de sectores de la socedad en a a almunitraction pubica somo estraliega t tive para luethar contra la des gualdad
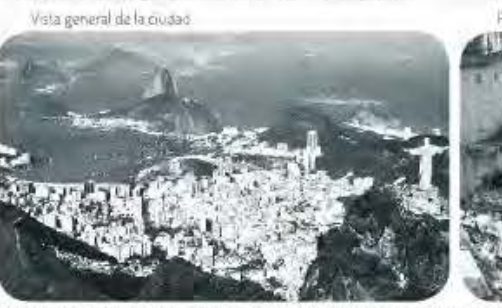

\section{MINISTERIO DE MEDIO AMBIENTE}

AGENDA LOCAL 21

Fierramuenta dit planficacon participativa para la construcción de sociedades sostenbles Combina métodos de protectión del medo
ambiente, justicia socal y écicencia economica

ZONIFICACION ECOLLGICA ECDNOMICA

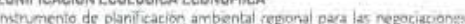

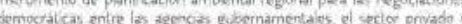
la sociedad uvil er un conjunto de poticas publitas para el desarrefí

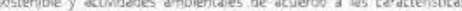
compatibles frestriccionas y posibitidaciesi) de cada uno de elios deaimita

\section{SUPERINTENDENCIA DE BIODIVERSIDAD Y FLORESTA}

Programa de ncentivo a ia creacicen e implaniación de Lnidades de

"onservacion Municipal (Conflictos: areas protegidas y las poblacienes)

- Productos de 50 C10 BIODAVERSIDAD= Projeclo uso sostenibie de

ENIACES DE CUUDADANAA Sortucones colectivas a los problemas ambientaes identírcados y la partiopación ce escuelas y comundad

\section{FAVELA - BAIRRO}

strategia de nteverenoion yrbarietica en busca de la integración

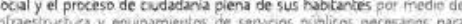
transformar las fave as en barrios formales de la ciudad A travees de una competereas de cispeno busco ol mantenimiento de

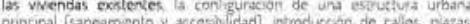

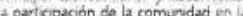

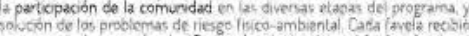
una agencia de cencoralizada = Centro de orientacon social y de urbarismo

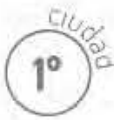

\section{a.}




\section{CIUDADDELCABO}

PROVINCIA: Occidental del Cabo-PAIS: Sudâfrica

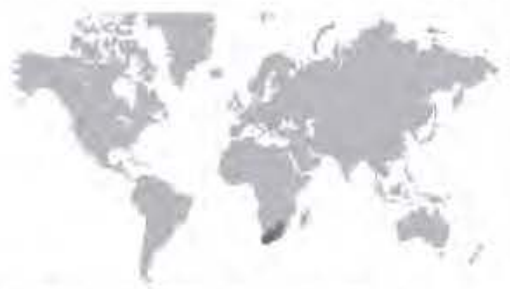

a Ciudad del Cabo se ónide administrativamente por

190 Suburbios (barrios)

Se situa en uno de los hotspot de buodiversidad mundial más amenazados. Posee una costa de $397 \mathrm{~km}$, dos cadenas de montañas, colinas y llanuras de berras bajas y soporta una ampla gama de ecosisternas naturales.

\begin{tabular}{|c|c|c|c|c|c|}
\hline Fundación de la Ciudad & EXTENSIONN CUUDAD & AREA URBANA & AREA RURAL & AREA INFORMAL, & OENSIDAOPOBLACIONAL \\
\hline จกี่ 1652 & $2.461 \mathrm{~km}^{2}$ & $446,8 \mathrm{~km}^{2}$ & 2.014 & $18,14 \mathrm{~km}^{2}$ & $1529 \mathrm{lab} / \mathrm{mm}^{2}$ \\
\hline
\end{tabular}

\begin{tabular}{|c|c|c|c|c|c|c|c|c|}
\hline $\begin{array}{l}\text { HABITANTES } \\
2011\end{array}$ & $\begin{array}{l}2^{\circ} \text { civodad } \\
\text { + poblada de } \\
\text { Sudiafrica }\end{array}$ & \multirow{2}{*}{\multicolumn{2}{|c|}{$\begin{array}{c}\text { HABITANTES cond. } \\
\text { pobreza } \\
\text { E35.804 }\end{array}$}} & \multirow{2}{*}{$\begin{array}{c}17 \% \text { de la } \\
\text { poblacion } \\
1 \text { ñin }\end{array}$} & \multicolumn{2}{|c|}{$\begin{array}{l}\text { Razones del } \\
\text { crediniento informal }\end{array}$} & \multirow{2}{*}{$\begin{array}{l}\mathrm{IDH} \\
0,82\end{array}$} & \multirow{2}{*}{$\begin{array}{l}\text { Espacio verde } \\
160 \text { inthits }\end{array}$} \\
\hline 3740.025 & & & & & \multicolumn{2}{|c|}{$\begin{array}{l}\text { geción des de Cabo Oriente } \\
\text { por pobreza y des fualdad }\end{array}$} & & \\
\hline Áreas protegidas urteanas & \multicolumn{2}{|c|}{ Huella de carbono } & \multicolumn{2}{|c|}{ PIB } & Tasa de natalidad & \multicolumn{2}{|c|}{ Mortalidad infantil } & Tasa analfabetisme \\
\hline $\begin{array}{l}16 \text { reservas } \\
\text { naturales }\end{array}$ & & 9,000 & & $\begin{array}{l}863 \\
\text { solates }\end{array}$ & 13 & & 9 & $1,8 \%$ \\
\hline
\end{tabular}

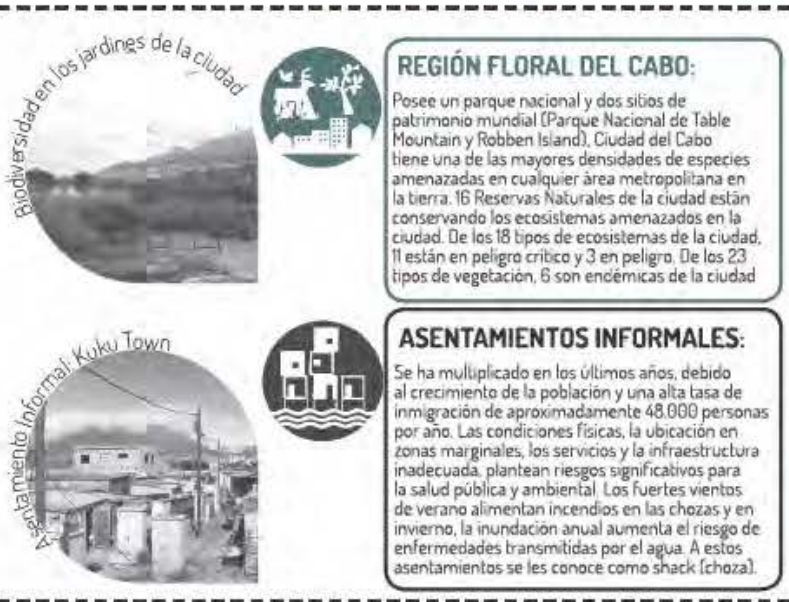

PROGRAMAS DE GOBIERNO Y AUTORIDADES AMBIENTALES

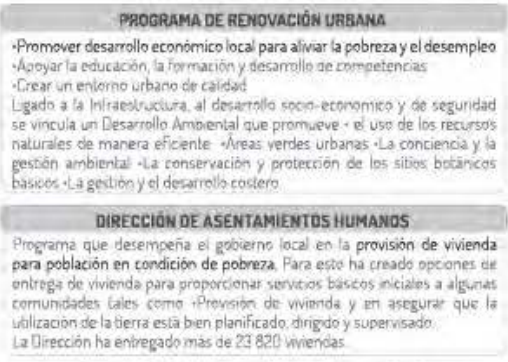

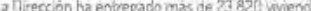

\section{ESOUEMA OE ZONHFCABSÖN CUUDAD OEL CABB}

Un unico esquema de zonficacion se ha introducido es la cudad en lugar

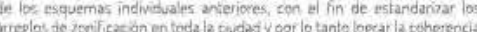

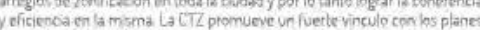
expaciales de la cudar a largo plazo y las policcas de uso del sueh y mejorar

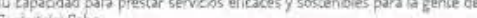
Curdad die Caho

\section{INSTTUTTO DE MEDIO AMAIENTE Y GESTOÓN DE RECREACIŌN}

tiene como obetivo ser la organizaón del settor súblico con la promocón de pracieras sostenibles e integradas de gestion ambental y la recrezcón
en Sudáriza.

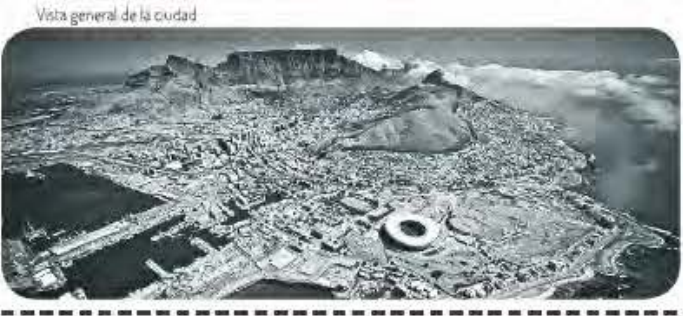

\section{CAPENATURE} conserracìn en los siguenes rogramas

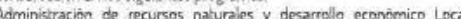

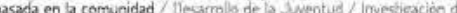

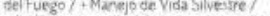
Gorretoonsabnitad inclusion de lerrenos privados y comunes en ef

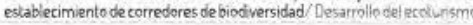

\section{MEP - Politica de integración Ambiental Metropolitana}

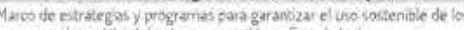

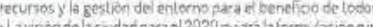

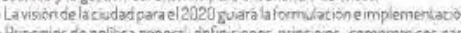

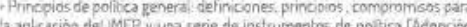

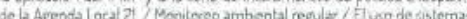

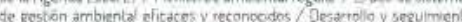

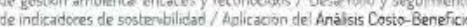
1 Acopcion y apication de princoios de la Gestion A mbiental Integrada mogramas de educacion arribienta en tedos los nivees de gobiema lac.

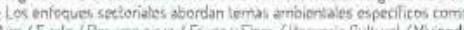

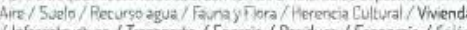
Infrestructura / Tronsporte / Energia / Resduos / Economia / Salo

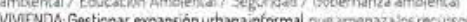

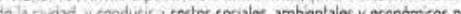

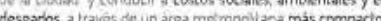
GOGERNANZA Aposo a proyectos amhientales mpulsados por b

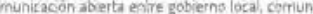

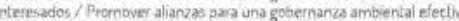
aclusión de las comindades en el proceso de toma de doctionn
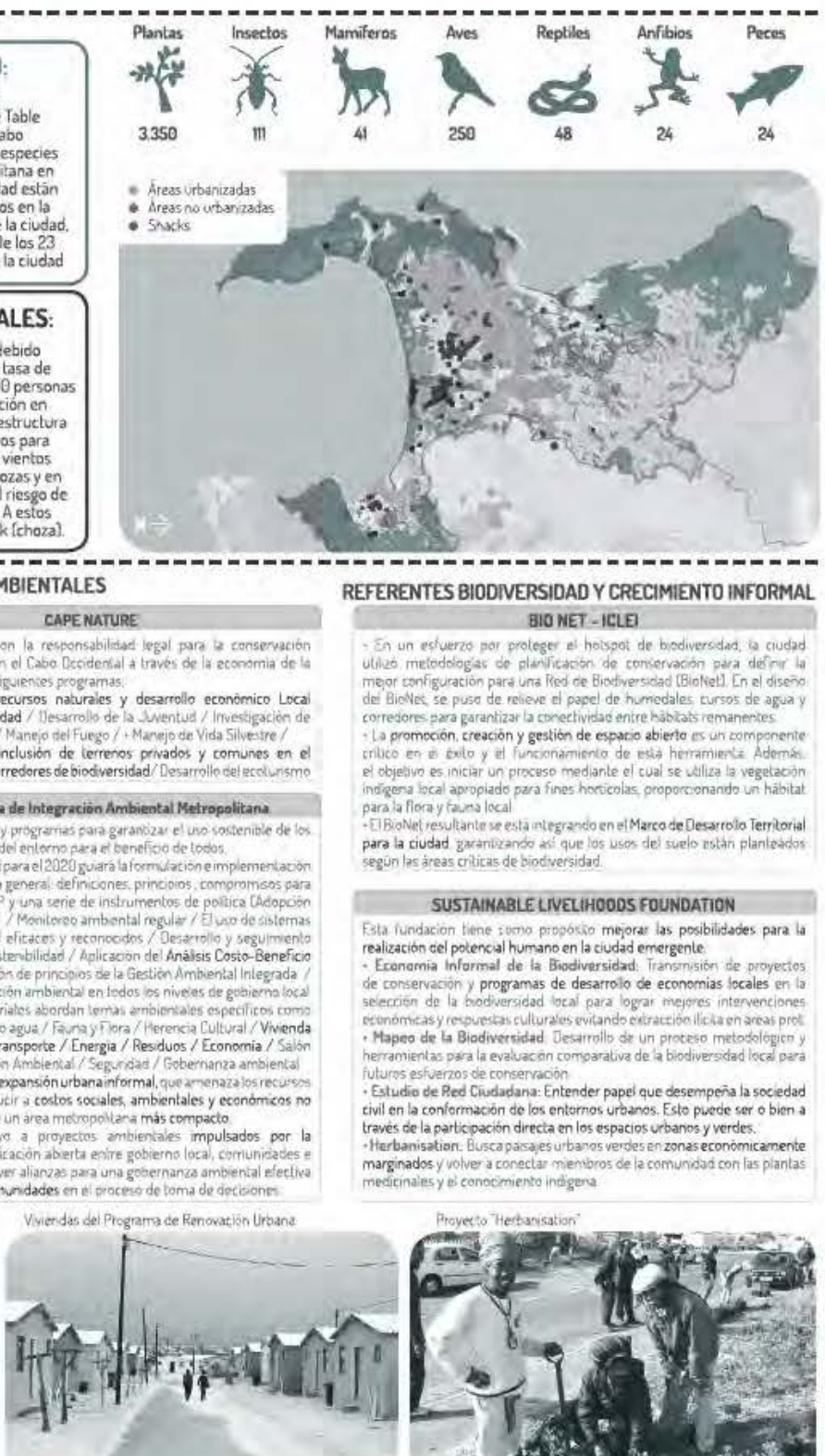

REFERENTES BIODIVERSIDAD Y CRECIMIENTO INFORMAL BIO NET - ICLE

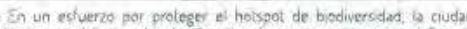

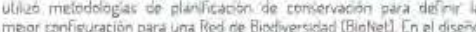
der Binkes. se puso de revieve ef papel de himedales tursos de arva crejors para garantizar la corectivisac entre hablats remanentes ta promoción. creación y gestion de espario abiento es un componentic Ret objetivo es iniciar un procesp med darte el cual se udiliza la vegetacon

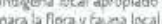

-13Bionet resultante se esta integrando en el Marca de Desarrolo Temitorial

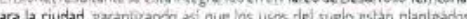
seguin las dreas criticas de biodiversidad

\section{SUSTAIKABLE LIVELIHOODS FOUNDATION}

Fsta fundacion thene zomo proposio mejorar las pesibilidades para to calizacion cel potencal humano en la ciudad emergente

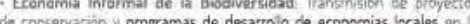
specriten de la bodversidad loeal para logar moines intenvenciones

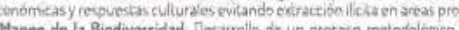

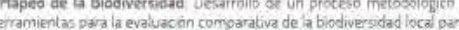

Entender papei que desemperia la sociedad tivil en la coniormacon de los entornos urados. Esto puede ser o bien. Iraves de la partapacion direcia en los espacios vebanos y verder.

Hertanisation aszapacsesula las os verdes en zonaseconomicamente marginadosy wive aconecte nientros do

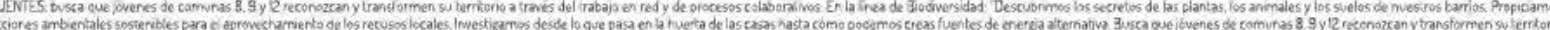

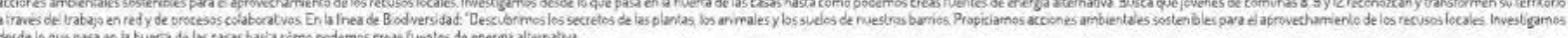

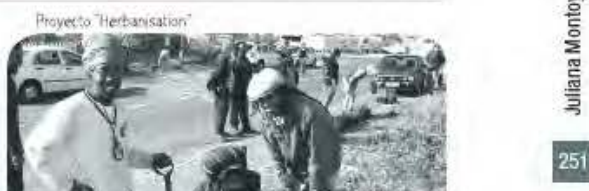




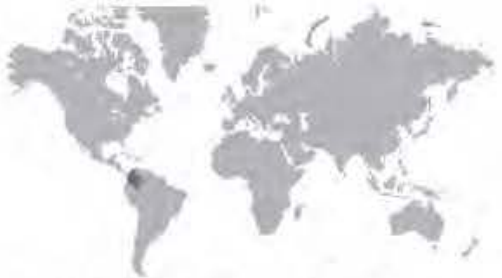

La ciudad de Medelin se divide administrativamente por:

6 corregmiento [rural] 249 barrios

16 Comunas [urbano]

20 Áreas Institucionales

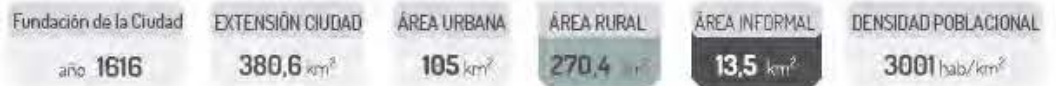

\begin{tabular}{|c|c|c|c|c|c|c|}
\hline $\begin{array}{l}\text { HABITANTES } \\
2014\end{array}$ & $\begin{array}{l}2^{\circ} \text { ciudad } \\
+ \text { +poblada de } \\
\text { Colombia }\end{array}$ & $\begin{array}{l}\text { HABTTANTES cond } \\
\text { pobreza }\end{array}$ & $\begin{array}{c}18.7 \% \text { de la } \\
\text { población }\end{array}$ & $\begin{array}{l}\text { Razones del } \\
\text { crecimiento informal }\end{array}$ & & Espacio publica \\
\hline $2 \cdot 464.322$ & & 401.708 & & $\begin{array}{l}\text { desplazameato por } \\
\text { pres or ce gruos armado }\end{array}$ & 0,6 & 3.9 \\
\hline
\end{tabular}

Áreas protegidas urbaras Huella de carbono PIB Tasa natalidad Mortalidadinfanti Tasa analfabetismo 44.393 3 S500.000
Toneladas
mitones doares 11,7

9,25

$3,17 \%$
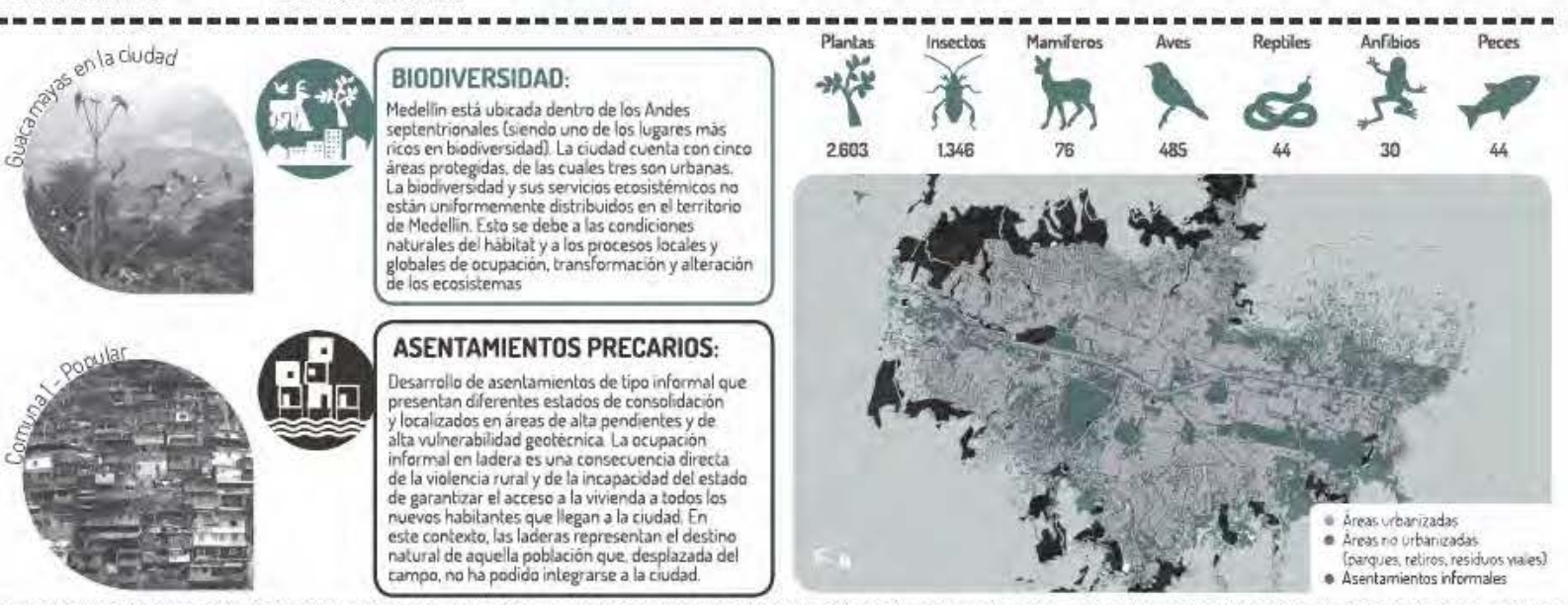

PROGRAMAS DE GOBIERNO Y AUTORIDADES AMBIENTALES

\section{JNRDIN CIRCUNVALAR}

como parte del Crisurón Verde Metropoliano es una estrategja para la

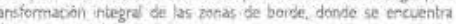

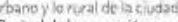

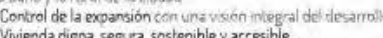

Suienda digna, segura sostenibley acces ble

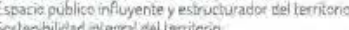

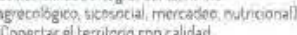

PRMEE - Programa Integral de Mejoramiento de Barrios

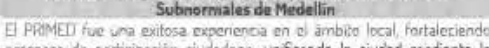
procesos de participación cividadana unificando la ciudad mediante la taldad de vida de los pobladores en estos sectores.

to construcción de canfianza entre las comunidades y el Estado

$2^{\circ}$ consirnucción de la capacidad técnica en el ámbito ocal

PUI-PROYECTO UREANOINTEGRAL

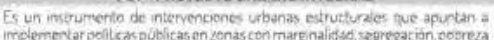

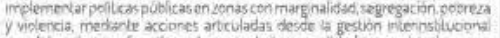

que iffera la coodinacon enire sectelarias y enidides muniopaies, para

eqecutar sinergicamente programas socales y proyectos de intervencon

Plan Estratégico Habitaciooal de Nedellin 2020 - PEHMED

Es una herramienta de polica pubica cue busca arentar ze queracer de

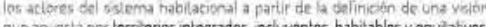

que apvesta por terrionos integrados, nduyentes, habilables y equidabos. precariefasily le apuesta a meigrar ia calicad de vida.

vista general de la oudad

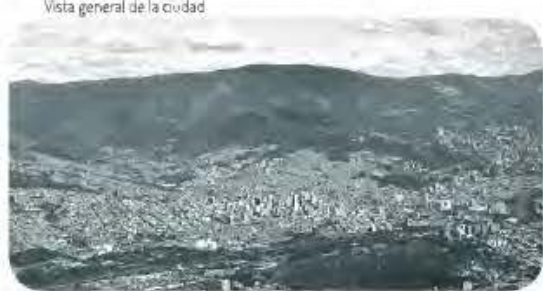

PGiBSE-Propuesta de Gestión Integral de la Biodiversidady Servicos Ecosiatemicos para Kedellin Construction de una polikica publica en bindiversdad y servcip

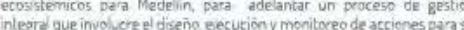

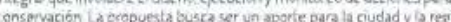
ton base enla consideracon de los wantessongeneracion de conocimento Yen las acciones reaicitadas en tonservacion de la biociversidad y setvicio ecosistemicos proponendes ln marco estratégco y oseraivo para la

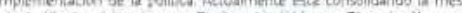

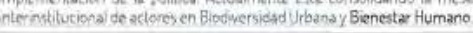
PARQUE CENTRAL DE ANTIOQUIA - Es una estrizegra de gestion y orderamiente urbano - iegonal, que senvicios ambientzies de la region cencral de Antioqua

Se tonc be como un sistema de áreary no temo uno sola ares proteged Parque Centrat ne Antioqua comprende un area de 894555 hiectareas y

- Por lo tanto agrupa los esfueros de todas las entidades ambientales are circundan los dez municopios del vale

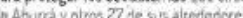

\section{PAM-Plan Ambiental de Medellin}

Forkaliecer ta planeación. Is gestion interinsbitusional y el desarricilo de

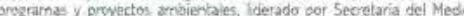

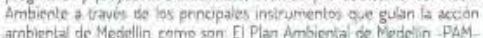
arnbiented de Medellin camo son El Plan Ambientar de Medelin PAA Gue es el instrumento técrico metodalogeco y operativo del Sistema oce

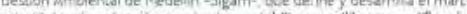

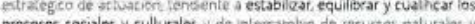
proceser sociales y culvales y de ntecainino de recursos nálurates

Soluciones de vivenda de acuerdo al PEHMED Senderos de Jardin Lircunvalar
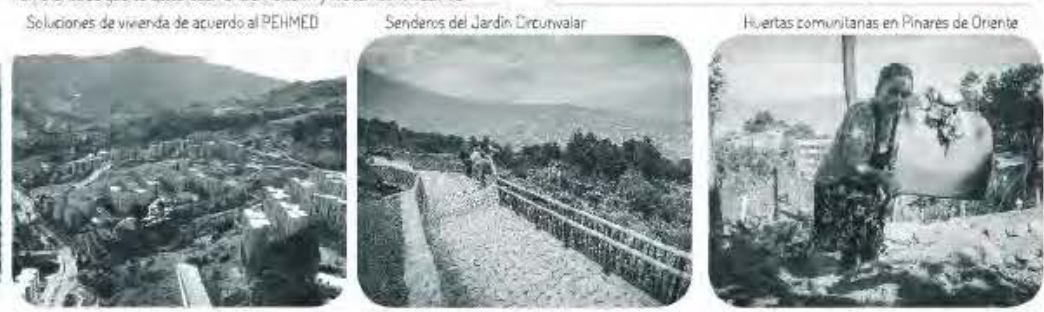

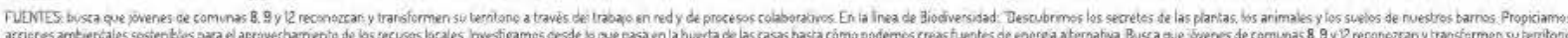

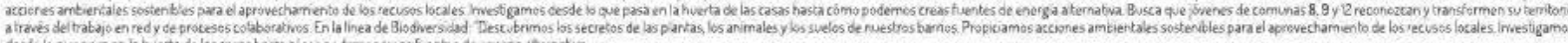



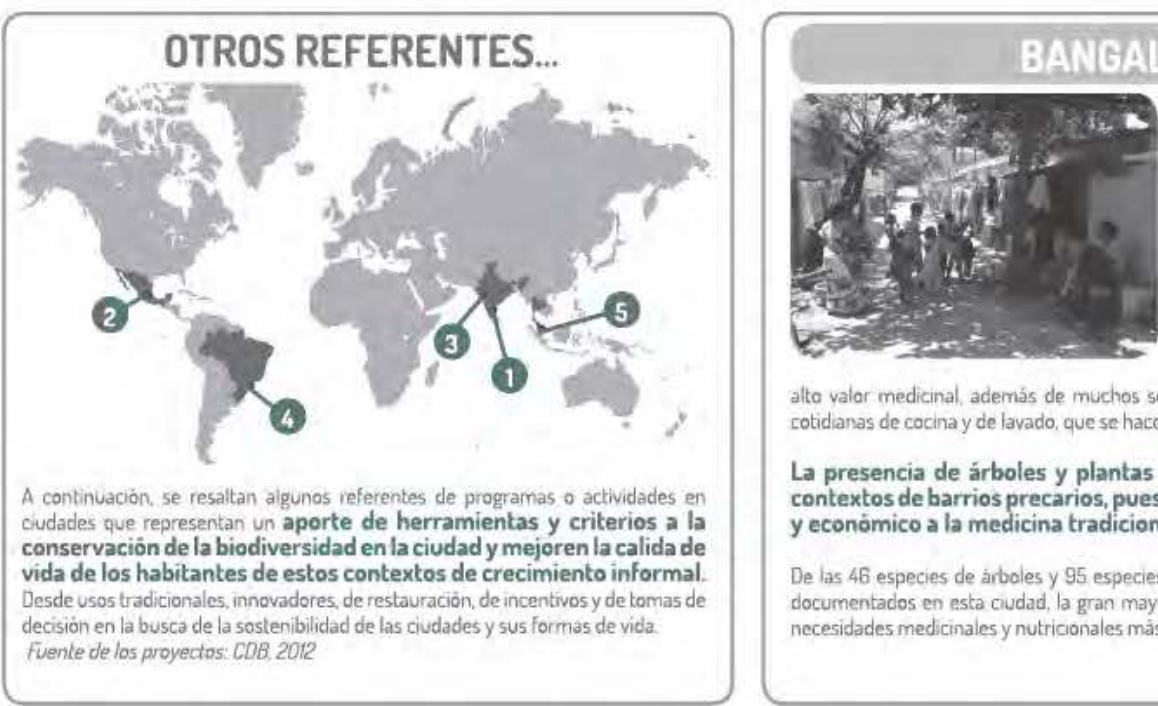
alto valar medicinal, además de muchos servicios socioculturales, como tareas cotidianas de cocina y de lavado, que se hacen bajo la sombra de los árboles.

La presencia de árboles y plantas medicinales son cruciales en contextos de barrios precarios, pues representan el acceso directo y económico a la medicina tradicional.

De las 46 especies de árboles y 95 especies de arbustos, hierbas y enredaderas documentados en esta ciudad, la gran mayoria son utilizados para satisfacer las necesidades medicinales y nutricionales más comunes.
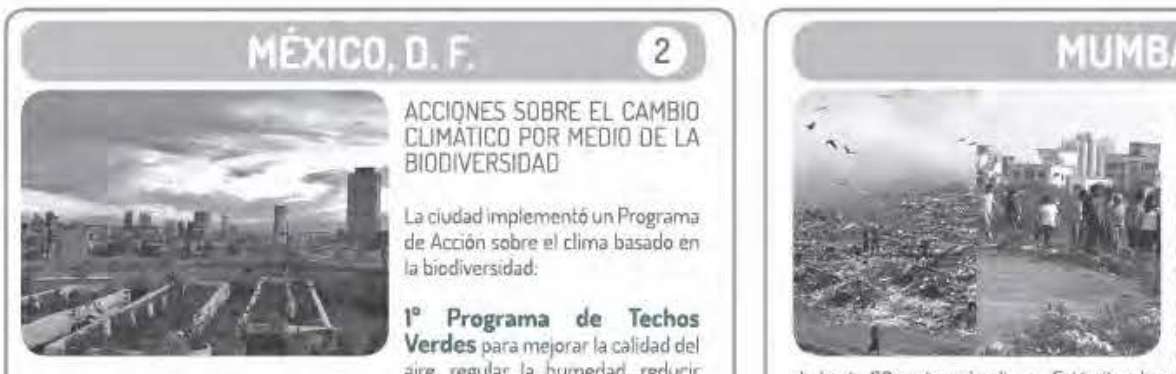

3

ACCIONES SOBRE EL CAMBIO CLIMATICO POR MEDIO OE LA BIODIVERSIDAD

La ciudad implemento un Programa de Acción sobre al clima basado en la biodiversidad:

$1^{\circ}$ Programa de Techos Verdes para mejorar la calidad del Las temperaturas y suministrar nuevos recursos de diversidad tiologica y cultivas alimentos en las azoteas, adicional a la educación ambiental de sus habitantes. Se otorgan descuentos en el pago del predial.

$2^{\circ}$ Programa de Rescate de los Ríos Magdalena y Eslava, enfocándose en los riespos por contaminación, mejorando sus condiciones ambientales y de los barrios cercanos.

$3^{\circ}$ Programa de restauración de ecosistemas y compensación para el mantenimiento de los servicios ambientales, dando incentivos a la comunidad y a los propietarios que protegen los recursos naturales esenciales y restauran los hábitats degradados.

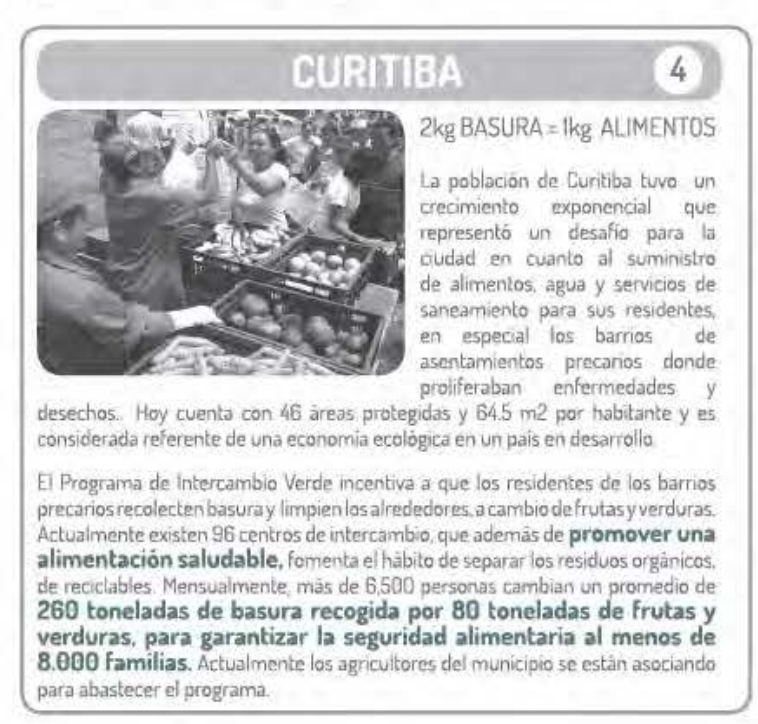
4he anos y con niveles de basura de hasta 26 metros de altura. Esta situado cerca a los suburbios occidentales de Mumbai, al lado de un arroyo y cerca de zonas residenciales, causando un daño ambiental significativo convirtiendose en uno de los lugares más insalubres de la ciudad.

Al clausurarlo se transformo en una zona verde de alta calidad con la posibilidad de instalar una planta de energia con gas melano generado por la basura en descomposicion.

El proyecto brindó beneficios para la salud pública, la calidad del agua, el espacio público, la valorización de las propiedades y del estilo de vida al transformar el hábitat de los residentes locales.

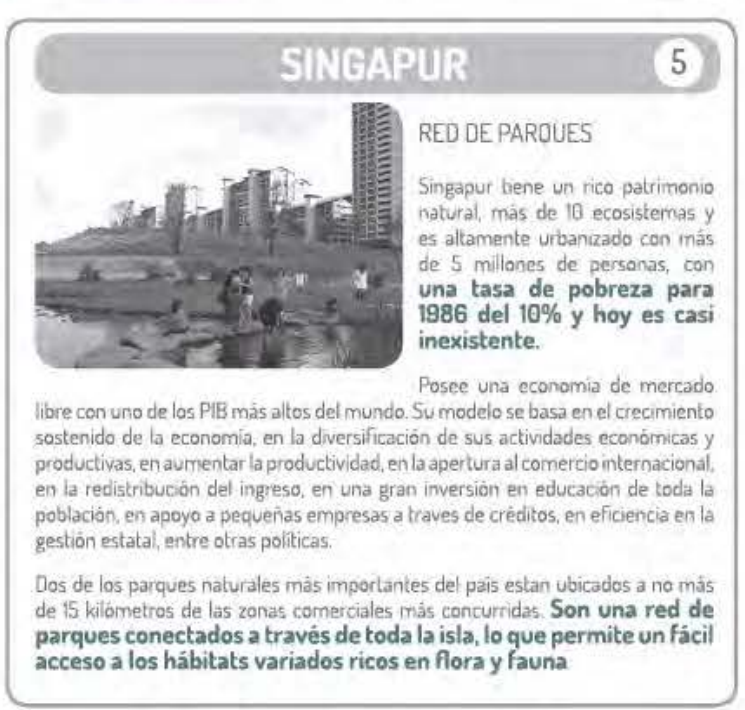




\section{Criterios y herramientas de planeación}

Los criterios y las herramientas de planeación son medios para lograr la comprensión, el desarrollo de estrategias y la intervención en el territorio. Los criterios responden a una visión de ciudad futura, son principios orientadores de hacia dónde quiere ir la ciudad. Por ejemplo, un criterio que forma parte del IMEP (Integrated Metropolitan Environmental Policy) de Ciudad del Cabo, y que forma parte de las metas planteadas por la Unesco, es el Desarrollo Sostenible que busca un equilibrio entre las necesidades ambientales, económicas, sociales y ecológicas. Los criterios o principios dieron orientación y marcos de acción para seleccionar las herramientas más apropiadas para el contexto específico. Estas son instrumentos con los cuales se obtienen efectos y aplicaciones directas sobre el territorio que cumplen con esos criterios. Por ejemplo, el Programa 21 de la ONU que busca promover el desarrollo sostenible (criterio) por medio de un plan detallado de acciones que requieren de atención mundial.

Luego de recopilar los criterios orientadores y las herramientas aplicadas de cada una de las ciudades analizadas, se clasificaron en tres grandes grupos:

, Biodiversidad: en donde los principales hallazgos responden desde una mirada ambiental. Se encontraron 6 criterios y en respuesta 24 herramientas para su aplicación.

, Crecimiento informal: estas visiones parten desde el enfoque del déficit de vivienda, la vulnerabilidad de sus contextos y la participación ciudadana. Se hallaron 15 criterios que responden a 23 herramientas de planeación.

, Integralidad: estos hallazgos son la respuesta tanto desde la biodiversidad, como desde el crecimiento informal, y que responden simultáneamente a los dos componentes. Se encontraron 9 criterios y 23 herramientas.

Estos 30 criterios y 70 herramientas halladas en programas y proyectos propuestos en las tres ciudades responden, a su vez, a 13 tipologías integrales que revelan la conexión con los enfoques de biodiversidad urbana y de servicios ecosistémicos urbanos vistos anteriormente (científico, cultural, social, económico, cambio climático, político, planeación):

1. Información (cambio climático y político)

2. Monitoreo (cambio climático y político)

3. Educación (científico y cultural)

4. Apropiación ciudadana (cultural, social)

5. Seguridad alimentaria (social y económico)

6. Adaptación (cambio climático)

7. Empleo (social y económico)

8. Uso sostenible (planeación)

9. Vivienda (social y económico)

10. Restauración ecológica (científico, planeación y económico)

11. Espacio público (social, cultural y planeación)

12. Conectividad (científico)

13. Política pública (planeación, político)

Es de aclarar que los criterios y herramientas presentados (las dos primeras columnas de las fichas de análisis de cada ciudad) nacen de dos escalas de planeación con intereses, objetivos, criterios y herramientas muy diferentes. Según Kattán y Valenzuela (2008) la planeación del territorio debe partir de dos análisis territoriales simultáneos, que parten de escalas diferentes y en direcciones convergentes: un análisis de planificación "de afuera hacia adentro" y otro "de adentro hacia afuera”, el cual se denominará en 
esta revisión como dinámicas top down y bottom up, respectivamente.

El top down o "de afuera hacia adentro", es llevado a cabo por lo general por agentes externos al territorio, como es el caso de organizaciones no gubernamentales de carácter nacional o internacional, o instituciones del Estado del mismo orden. Por lo general, las estrategias de planeación y formulación de la política desde el gobierno en materia ambiental parten de la selección de un espacio geográfico, de importancia biofísica y sociocultural, que se constituye en la unidad de planificación e implementación de acciones de conservación a gran escala. Con esto se busca armonizar las acciones con los intereses y las demandas de uso del suelo para el desarrollo económico, lo cual implica una gestión sobre espacios naturales, paisajes rurales y entornos urbanos (Bejarano, 2014 y Urbina-Cardona y Agudelo, 2011).

Algunas estrategias de planeación en esta escala institucional, adicionales a las ya presentadas, $y$ que vale la pena mencionar son:

, La Estructura Ecológica Principal (EEP): es la red de espacios y corredores que sostienen y conducen la biodiversidad y los procesos ecológicos esenciales por medio del territorio, en sus diferentes formas e intensidades de ocupación, dotándolo al mismo tiempo de servicios ambientales para el desarrollo sostenible (Andrade, Mesa, Ramirez y Remolina, 2008).

, Infraestructura verde: es una red estratégicamente planificada de espacios naturales y seminaturales y otros elementos ambientales diseńados y gestionados para ofrecer una amplia gama de servicios ecosistémicos. Incluye espacios verdes (o azules si se trata de ecosistemas acuáticos) y otros elementos físicos en áreas terrestres (naturales, rurales y urbanas) y marinas (Tzoulas, Korpela, Venn,
Yli-Pelkonen, Kaźmierczak, Niemelä y James, 2007).

Mejoramiento integral de barrios en Colombia: es una estrategia para reducir la pobreza urbana y para la integración e inclusión de los asentamientos precarios dentro de la estructura funcional y productiva de la ciudad (Ministerio de Vivienda, Ciudad y Territorio; o Conpes 3604 de 2009)

Política pública de ecourbanismo y construcción sostenible de Bogotá: su objetivo general es reorientar las dinámicas de urbanismo y construcción de Bogotá con un enfoque de desarrollo sostenible: 1) lograr que en toda decisión de arquitectura, urbanismo y construcción se incorporen prácticas sostenibles; 2) fortalecer la capacidad de respuesta institucional para la aplicación de prácticas sostenibles en urbanismo y construcción; 3) promover incentivos que permitan que el sector de la construcción incorpore gradualmente criterios de sostenibilidad; 4) lograr la apropiación de las prácticas de ecourbanismo y construcción sostenible por parte de los diferentes sectores sociales (Alcaldía Mayor de Bogotá D. C. et al., 2014).

, Criterios ambientales para el diseño y construcción de vivienda urbana: se busca contribuir al desarrollo sostenible de las áreas urbanas, con un conjunto de propuestas de gestión ambiental y de enfoque principalmente preventivo. Se centran en la atención de los principales problemas ambientales de la vivienda urbana, al ser identificados desde la etapa del diseño de la vivienda. Así mismo, se incluyen propuestas para las etapas de construcción y uso de la vivienda, con lo cual se desea contribuir a mejorar la salud y la calidad de vida de la población colombiana, en especial de los grupos más vulnerables (Ministerio de Ambiente y Desarrollo Sostenible, 2012a y 2012b). 
Ahora es preciso aterrizar estas estrategias en nuestro escenario de interés que son los asentamientos informales, ya que se presentan como estrategias generalizadoras que consideran las problemáticas de estos contextos y de sus habitantes a una escala muy amplia sin tener en cuenta múltiples peculiaridades y complejidades de estos territorios espontáneos (Urbam, 2013).

El bottom up o "de adentro hacia afuera" resulta cuando la planificación se realiza a partir de procesos locales, desde las aspiraciones y las expectativas de distintos actores locales dentro de un mismo territorio (Kattán y Valenzuela, 2008). Dado que los intereses de quienes ocupan porciones de un gran territorio están definidos en gran medida por las necesidades de permanencia en el mismo, las metas locales por lo general incluyen:

, Incremento en la participación en la toma de decisiones sobre el uso de la tierra.

, Incremento en la seguridad y soberanía alimentaria.

, Resolución de conflictos por el acceso a recursos.

, Mantenimiento de atributos singulares de importancia simbólica.

- Recuperación de funciones críticas para la calidad de vida.

> Prevención de desastres.

El punto de convergencia de ambas escalas, define un escenario ideal para articular criterios y herramientas con una visión de integralidad hacia el uso y la conservación de la biodiversidad en las ciudades, por medio de lo que llamaremos en esta revisión como "acciones locales para la biodiversidad en contextos informales", y que explicaremos a continuación.

\section{Acciones locales para la biodiversidad}

Para traducir los criterios abstractos de la biodiversidad en herramientas aplicables en lo práctico, o en acciones, los conocimientos deben hacerse ajustables al contexto local y regional (Elander et al., 2005), deben ser definidos por sus propios habitantes y acompañados por instancias institucionales. Dicho de otra forma, se busca poner en relieve los procesos de transformación que surgen desde el bottom up (organizaciones de base) y el top down (políticas públicas o entidades) en ámbitos urbanos y rurales, y valorar esta convergencia territorial y social que permite la integración de la comunidad, la academia, las organizaciones de base, las políticas públicas y el sector privado (Urbam, 2013) para el desarrollo de acciones precisas acerca de la biodiversidad en contextos de crecimiento informal.

Tal como dicen Andrade y Wills (2010), ya no se trata de mantener los esquemas tradicionales de generación de conocimiento público basado exclusivamente en estructuras estatales burocráticas, que definieron sus prioridades y sus campos de investigación y de acción en una perspectiva top down, a partir del conocimiento de unos pocos expertos. Se requiere reconceptualizar dichos esquemas hacia formas de generación de conocimiento cooperativo, con la conformación de redes en las que participen actores gubernamentales, privados y de la sociedad civil, con el objetivo de lograr que el conocimiento generado sea legítimo y efectivo.

Por lo anterior se formula la siguiente reconceptualización multinivel, que será punto de partida para la propuesta de acciones para la biodiversidad: 1) el crecimiento informal, desde una mirada bottom up, ya que son los habitantes que viven en estos contextos los principales 
planeadores de su territorio; 2) la biodiversidad urbana, vista desde top down, ya que son los gobiernos, instituciones y demás organizaciones las que tienen conocimiento y herramientas de la biodiversidad a una escala general; 3) la gobernanza integral como el elemento integrador de las dos primeras, que orienta la toma de decisiones (ver Tabla 3).

Tabla 3.

Bottom up: inclusión del crecimiento informal. Top down: planeación de la biodiversidad urbana.

Gobernanza integral como elemento integrador de ambos flujos de relaciones

Inclusión del crecimiento informal

Bottom up
Planeación de la biodiversidad urbana Top down
En estos contextos informales la migración tiene diferentes lugares de procedencia, por lo que presenta un grado alto de diversidad cultural, la concurrencia de varias formas de conocimiento, y el diálogo y traducción de saberes, que se constituyen en aspectos básicos para la construcción de acuerdos de gestión en los espacios de la biodiversidad (Andrade y Wills, 2010). En este sentido, el conocimiento como una forma de capital social, y su posible movilización en procesos de toma de decisiones, se constituye en un elemento central de la capacidad adaptativa y de resiliencia en los sistemas socioecológicos (Walker y Salt, 2006).

Cuanto más locales sean las prácticas de planificación y de diseño, mejores serán los resultados en términos de conservación de la biodiversidad, ya que los planificadores locales suelen estar mejor informados y son potencialmente más flexibles para reaccionar ante los desafíos particulares (CBD, 2012).
Ciudades, gobiernos nacionales, académicos y organizaciones internacionales han elaborado una amplia cartera de herramientas políticas, directrices, proyectos e instituciones que promueven la preservación de la diversidad biológica (CDB, 2012). La gestión exitosa de la biodiversidad y de los servicios de los ecosistemas puede basarse en un compromiso de escala múltiple, de sectores múltiples y de múltiples interesados directos (Elander et al., 2005 y CDB, 2012). Los esfuerzos para esta gestión van a provenir de todos los sectores y niveles de toma de decisiones (CDB, 2012), en donde la cooperación es importante para sincronizar y armonizar acciones multiescalares (internacional, nacional, subnacional y local) y multidimensional (en el ámbito ambiental, de planeación, de movilidad, de educación, de economía y de nutrición), siendo los gobiernos locales los que tienen mandatos fundamentales en términos de impuestos y distribución de las inversiones para la infraestructura de las ciudades, esenciales para que cualquier presupuesto municipal ecológico funcione (ICLEl, 2010 y CDB, 2012).

\section{Referente de procesos de planificación} Bottom up

- "Participate"-knowledge from the margins for post-2015:

Es una red de 18 organizaciones de investigación participativa que trabaja con los grupos pobres y marginados en 29 países.

Sus objetivos son evidenciar las perspectivas de los que están en la pobreza en los procesos de toma de decisiones, por medio de la investigación participativa, y asegurar que las personas marginadas tienen un papel central en la toma de decisiones y la generación de conocimiento, comprensión y relaciones para el bien público global.

Algunas actividades incluyen:

- La creación de Ground Level Panels (GLP) que consolida la experiencia de las personas en situación de pobreza hacia conclusiones en torno al futuro del desarrollo y producen sus propias recomendaciones.

- Procesos visuales con acceso a cámaras para facilitar la comprensión de su cotidianidad como forma de investigación.

\section{Referente de procesos de planificación} Top down

- ICLEI- Gobiernos Locales por la Sustentabilidad:

Es una asociación internacional de gobiernos locales y metropolitanos comprometida con la construcción de un futuro sostenible. Promueve la acción local para la sostenibilidad global y apoya ciudades para que sean resistentes, eficientes en recursos, biodiversidad, baja emisión de carbono sostenible, infraestructura inteligente y desarrollar una economía verde urbana inclusiva.

Tienen múltiples programas de apoyo:

- Por medio de Local Action for Biodiversity (principal referente para la propuesta de este trabajo) reconoce el papel de los gobiernos locales en la gestión sostenible de la biodiversidad urbana, en 5 pasos: evaluación de la biodiversidad, compromiso político, planificación, aprobación política e implementación 
- Facilitar un grupo de investigación participativa global con talleres metodológicos para la reflexión, la innovación y la documentación de los procesos involucrados. Estas actividades son desarrolladas bajo enfoques metodológicos participativos.

La capacidad que tienen las personas que viven en la pobreza y la marginación para crear conocimiento como evidencia de sus propios problemas y para reconocer el valor de ese conocimiento por medio de procesos de investigación participativa, puede resultar en una iniciativa de investigación, en donde los participantes crean su propio espacio en el debate mediante la participación de los propios miembros de la comunidad, así como en grupos de interés externos.
- Urban Biosphere Initiative (URBIS): una búsqueda para generar ciudades con mayor capacidad de recuperación socioecológica en el contexto del cambio ambiental global. La iniciativa se alinea con los esfuerzos internacionales más amplios para aplicar el enfoque por ecosistemas y construir economías verdes urbanas.

- Urban Biodiversity and Ecosystem Services (URBES): fue un proyecto de investigación sobre los vínculos entre la urbanización, servicios de los ecosistemas y la biodiversidad.

- Global Biodiversity Information Facility (GBIF): es una red voluntaria de biodiversidad nacional, regional y temática en diferentes países, que proporciona los medios para acceder a los datos científicos en Internet.

\section{Gobernanza integral para la conservación de la biodiversidad en contextos informales}

Young (1996) define la gobernanza como: "Una función social cuyo desempeño es crucial para la viabilidad de todas las

sociedades humanas; se centra en la gestión de complejas interdependencias entre los actores (ya sean individuos, corporaciones, grupos de interés, 0 agencias públicas) que participan en la toma de decisiones interactivas y, por lo tanto, la adopción de medidas que afectan el bienestar de los demás" (p. 2). La gobernanza integral es un fenómeno de múltiples ámbitos como el familiar, el comunitario, en el barrio, la ciudad, el pueblo, la región, la nación, o el contexto global (Elander et al., 2005).

La inclusión de la sociedad civil y de los grupos de interés son vitales en las iniciativas de políticas gubernamentales locales para la gestión efectiva de la biodiversidad (Elander et al., 2005). Además, dado que los grupos de interés y los actores locales tienen una influencia directa sobre esta gestión, los mecanismos de política deben diseñarse e implementarse en conjunto con iniciativas sociales, con el fin de crear redes adaptativas y policéntricas (Barthel, Colding, Elmqvist y Folke, 2005).

\section{Kit de herramientas}

Luego de haber profundizado en los flujos del crecimiento informal como bottom up, la biodiversidad urbana como top down, y el elemento que los integra por medio de la gobernanza ambiental, se presentan a modo de Kit de herramientas (ver Figura 11), las acciones locales para la biodiversidad en contextos informales. Cada una de ellas intenta dar respuesta a ambos flujos por medio de diferentes experiencias y referentes de proyectos o programas, algunos ya presentados en el análisis de las ciudades, solo que esta vez se enfocan en el cumplimiento de las acciones locales para la biodiversidad en contextos informales (ver Tabla 4).

Figura 11.

Kit de herramientas de las Acciones locales para la biodiversidad en contextos informales

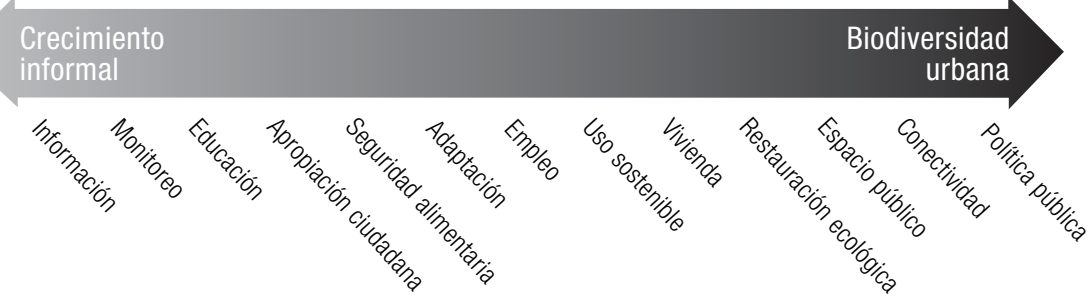

Fuente: elaboración propia (2015) 
Tabla 4.

Kit de herramientas

Herramienta número 1 - Información

Para cualquier proceso de gestión de la biodiversidad, el punto de partida es el estado de conocimiento acerca del territorio, es decir, la información existente para comprender las características específicas de la ecología sociodemográfica y el desarrollo urbano local antes de llevar a cabo investigaciones en el campo. Bases de datos sobre temas ecológicos nacionales, regionales y locales pueden proporcionar información valiosa. Por otra parte, las encuestas existentes, discos, fotos, mapas, proyectos y estudios relacionados con los ecosistemas de la ciudad y los cambios ambientales también pueden ser valiosos. En ausencia de datos disponibles públicamente, entrevistas con varios expertos y ciudadanos experimentados pueden dar una alusión general de la situación (de Oliveira, Shih, Wan-yu, Moreno-Peñaranda y Phillips, 2014).

Bottom up-Referentes
Cartografía Social-(Medellín).
Programa Territorio Expandido Laboratorio de prácticas barriales.
A partir de las herramientas cartográficas y la elaboración
de mapas, se potencia los procesos de lectura crítica de las
territorialidades y empoderamiento de la comunidad.

http://www.parqueexplora.org/territorioexpandido

\section{Top down-Referentes}

Sistema Municipal de Información Urbana-(Río de Janeiro)

Recopilar, gestionar, integrar y actualizar el conjunto de información sobre la ciudad, establecida en un canal eficiente de comunicación entre las agencias con el fin de apoyar las políticas públicas de la administración municipal. http://www.rio.rj.gov.br/web/ipp/siurb

\section{Herramienta número 2 - Monitoreo}

Se trata de la observación y supervisión del estado de parámetros sobre el territorio para detectar eventuales cambios, anomalías, oportunidades y presiones. La observación va dirigida tanto a los componentes naturales del territorio, como a los cambios físicos del entorno como la expansión urbana por nuevos habitantes.

Bottom up-Referentes Top down-Referentes

Guardianes ambientales-(Río de Janeiro)

Como parte del programa de inclusión social de la municipalidad, se busca la promoción de la observación y conciencia ambiental de las comunidades involucradas.

http://www.rio.rj.gov.br/web/ipp/programasde-inclusao-da-prefeitura
El índice de la Biodiversidad en la ciudad-(Singapur)

Herramienta de autoevaluación para vigilar y evaluar el progreso de las ciudades en la conservación y mejora de la biodiversidad con 23 indicadores en tres componentes: la biodiversidad nativa, los servicios de los ecosistemas y de gobierno, y gestión de la biodiversidad

http://cbc.ICLEl.org/cbi

\section{Herramienta número 3 - Educación}

Andrade y Wills (2010) señalan que hay que tener especial atención en educar e informar a los ciudadanos y tomadores de decisiones sobre los méritos de la preservación de la biodiversidad y la protección de la naturaleza, así como también en temas de expansión urbana, usos del suelo e implantación de las viviendas con respecto a su entorno. McKinney (2002) establece que un público bien informado puede actuar como el medio más importante para promover la conservación eficaz de las especies nativas.

Bottom up-Referentes

A Mata Atlântica é Aqui-(Río de Janeiro).

Camión adaptado para servir de escenario de actividades educativas y culturales que recorre diferentes comunidades, con el objetivo de estimular la diversión y el interés para que los niños y los adultos adopten actitudes sostenibles.

https://www.sosma.org.br/projeto/a-mata-atlantica-e-aqui/

\section{Top down-Referentes}

Desarrollo de la Juventud-(Ciudad del Cabo)

El uso de actividades como una herramienta para el desarrollo de los jóvenes por medio de la transmisión de conocimiento sobre el patrimonio, la comprensión de su importancia y el aprendizaje de habilidades para su conservación.

http://www.capenature.co.za/care-for-nature/kid-zone/get-educated/ 
El reconocimiento de los habitantes de un territorio como ciudadanos por medio de la apropiación es vital para la gestión de su entorno, tanto para la biodiversidad como para el crecimiento informal, pues son estos actores lo que tienen influencia directa en las condiciones físicas, por el uso y manejo que le dan a su territorio. Estos contextos informales resultan ser socialmente autoorganizados, muchos grupos de intereses y colectivos trabajan para cumplir objetivos.

Bottom up-Referentes
Civic Network Study-(Ciudad del Cabo).
Es un programa de la Fundación de Medios de Vida Sostenibles
que busca la comprensión del papel que desempeña la sociedad
civil en la conformación de los entornos urbanos y cómo la "red
de relaciones" es fundamental para tomar medidas y poner
nuevos temas en la agenda de la ciudad. Pero también para crear
cierta autonomía en la sociedad civil en relación con los actores
estatales y privados. El objetivo final es comprender mejor cómo
se juega la colaboración entre el Estado y la sociedad civil.

http://livelihoods.org.za/projects/civic-network-study
Top down-Referentes

PRIMED-Programa Integral de Mejoramiento de Barrios Subnormales-(Medellín)

Acciones de intervención construidas como herramienta pedagógica para el fortalecimiento de la capacidad social y comunitaria de interlocución con el Estado, en las que, explícitamente, la intervención física fue un pretexto para el conocimiento y administración de lo público, en un ejercicio que potencialmente apuntó hacia la construcción de una ciudadanía plena.

http://www.edu.gov.co/index.php/proyectos/ proyectos-urbanos-integrales

Herramienta número 5 - Seguridad alimentaria

En las ciudades existe una relación directa entre la diversidad biológica y la seguridad alimentaria. La diversidad biológica en sistemas alimentarios urbanos cumple un papel fundamental en la lucha contra el hambre y en los problemas de salud relacionados con la dieta. Es sumamente importante para la configuración de sistemas alimentarios con capacidad de recuperación (CBD, 2012).

$$
\text { Bottom up-Referentes }
$$

Huerta comunitaria Pinares de Oriente-Medellín).

La implementación de huertas comunitarias fue una iniciativa de los propios habitantes debido a su origen y vocación campesina. Estas buscan el fortalecimiento de la vocación agrícola de la población. El proyecto es liderado por la mesa de desplazados de la comuna 8 y es apoyado por entidades como la Secretaría de Gobierno, la Empresa de Desarrollo Urbano y la Universidad Nacional sede Medellín, entre otras, para el mejoramiento y optimización de los sistemas productivos.

https://www.flickr.com/photos/ciudadcomuna/ sets/72157644405606703/
Top down-Referentes

Intercambio verde-(Curitiba)

Alienta a que los residentes de los barrios precarios limpien los alrededores, y mejoren la salud pública al ofrecer fruta fresca y verduras a cambio de la basura y los residuos que se llevan a los centros dispuestos en el vecindario. En 2012 Curitiba contaba con 96 centros de intercambio. Todos los meses, más de 6.500 personas cambian un promedio de 255.416 kilos de basura recogida por 92.352 kilos de frutas y verduras.

http://www.curitiba.pr.gov.br/noticias/moradores-doxaxim-ganham-ponto-do-cambio-verde/25331

\section{Herramienta número 6 - Adaptación}

Los espacios verdes urbanos pueden aumentar el almacenamiento y la captura de carbono. Estos espacios ofrecen muchos servicios de los ecosistemas, entre estos, sombra, intercepción e infiltración del agua lluvia, reducción de la contaminación, así como reducir significativamente el efecto de las islas de calor urbano. Los bosques pueden contribuir indirectamente a la mitigación del cambio climático al brindar más sombra y frescura, y así, reducir el consumo total de energía (CBD, 2012), siendo los asentamientos informales los más vulnerables a los efectos del cambio climático.

Bottom up-Referentes

Re-habitar la Montaña-(Medellín)

Estudio que desarrolla estrategias y procesos para un hábitat sostenible en las laderas de Medellín, por medio de un modelo de gestión inclusivo y participativo. Dos de sus cinco propósitos tienen que ver con adaptación:

- Anticipar desastres por medio de alarmas, sensores y sistemas de evacuación.

- Mitigar el riesgo por medio del manejo de agua lluvia y la estabilización de taludes.

http://issuu.com/universidadeafit/docs/rehabitar-monta__a
Top down-Referentes

Ecocasas con bajas emisiones de carbono (México)

Apoya la construcción de 27.000 viviendas eficientes que contribuirán a reducir un $20 \%$ las emisiones de gases de efecto invernadero y mejorar con ello la calidad de vida de las familias de bajos ingresos. Entre estas tecnologías se destacan el aislamiento del techo y las paredes, el uso de pintura reflectante, calentadores de gas eficientes, frigoríficos eficientes 0 ventanas que permiten ahorrar energía. Sin embargo, sigue haciendo falta la inclusión de la biodiversidad como componente fundamental en estas propuestas de vivienda. http://www.un.org/climatechange/es/ blog/2014/08/ecocasa-low-carbon-housing-mexico_es/ 
Una característica compartida de estos contextos de asentamientos informales, es que por lo general sus habitantes tienen empleos informales con los que no alcanzan a obtener recursos para acceder a vivienda formal. Una alternativa interesante para aplicar en estos territorios es mediante la vinculación de la comunidad a procesos de conservación y usos de la biodiversidad, con el fin de garantizar ingresos económicos a sus habitantes y la protección de su entorno natural, que, a su vez, representa su bienestar humano.

$$
\text { Bottom up-Referentes }
$$

Economía informal de la biodiversidad-(Ciudad del Cabo).

Partiendo de una economía informal que se vive en la ciudad a partir de la biodiversidad, nace este proyecto que busca continuar estos empleos pero por medio de la transmisión de proyectos de conservación y programas de desarrollo de economías locales en la selección de la biodiversidad local para lograr mejores intervenciones económicas y respuestas culturales, para evitar la extracción ilícita en áreas protegidas.

\section{Top down-Referentes}

Proyecto Jucara-sociobiodiversidad-(Río de Janeiro).

Se basa en la difusión y expansión del uso de los frutos de la palma juçara (palma) para la producción de pulpa para alimentación y su uso en la cocina. Se busca la consolidación de su cadena de producción mediante la difusión de la gestión sostenible de los juçara en actividades de generación de ingresos asociados a la recuperación de la especie y la Mata Atlántica. También se propone la reconversión productiva de las áreas, lo que contribuye a la retención de carbono.

http://www.projetojucara.org.br/

\section{Herramienta número 8 - Uso sostenible}

Los Principios y directrices de Addis Abeba para la utilización sostenible de la diversidad biológica consisten en catorce principios empíricos interdependientes, directrices operativas y algunos instrumentos para su aplicación, que rigen los usos de los componentes de la diversidad biológica para garantizar que sean sostenibles. Proporcionan un marco para ayudar a los gobiernos, los administradores de recursos, las comunidades indígenas y locales, el sector privado, y otros interesados directos, a asegurar que su uso de los componentes de la diversidad biológica no lleve en el largo plazo a su declinación (CBD, 2010). Usar la biodiversidad de una manera sustentable significa usar los recursos naturales a una velocidad tal que la tierra pueda renovarlos. Es una manera de asegurar que cumplamos con las necesidades de las generaciones presentes y futuras.

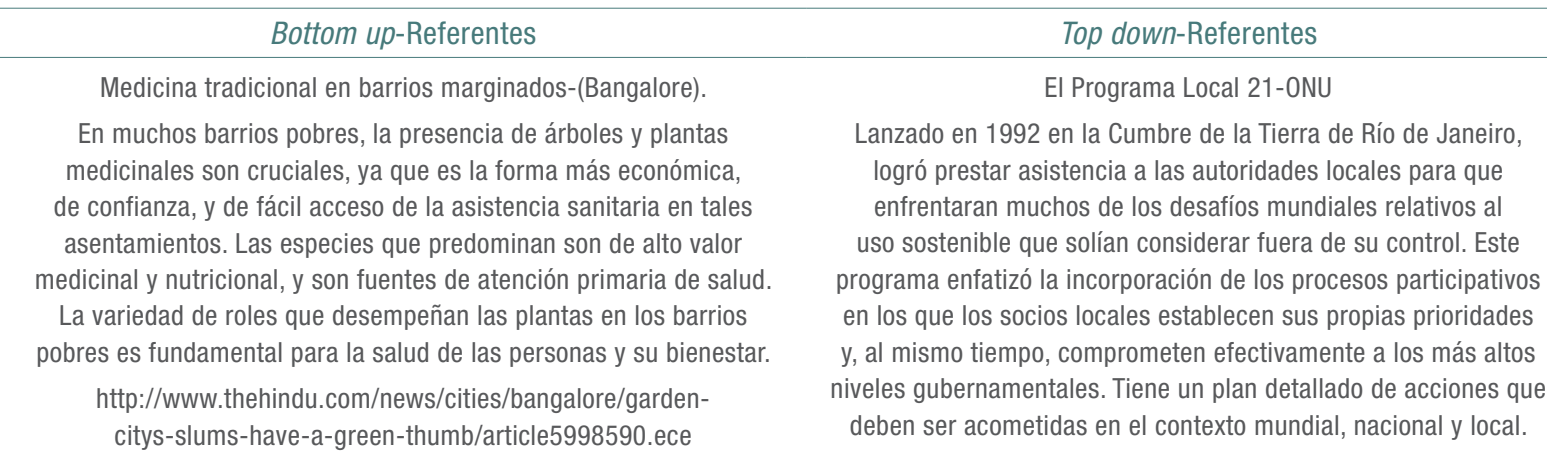

http://www.un.org/spanish/esa/sustdev/agenda21/

Herramienta número 9 - Vivienda

Este es el tema más controversial de las herramientas, pues es un derecho básico y fundamental para cualquier persona, y es razón principal por la que se da la expansión urbana y el crecimiento informal. El desafío está en integrar intervenciones físicas en el territorio, con consideraciones acerca de su entorno, en busca de reconocer los servicios que presta el ecosistema, teniendo en cuenta la conservación de la biodiversidad.

\begin{tabular}{|c|c|}
\hline Bottom up-Referentes & Top down-Referentes \\
\hline Hábitat para la mujer-Comunidad María_Aux-(Bolivia) & Incentivos y medidas para el cambio climático-(México) \\
\hline $\begin{array}{l}\text { Este proyecto, iniciado y administrado por la comunidad, implica } \\
\text { un modelo de fondo comunitario para la legalización de la tierra y } \\
\text { la autoconstrucción de vivienda para las familias de bajos ingresos, } \\
\text { según un modelo progresivo. Este enfatiza el papel de la mujer, } \\
\text { quienes reciben capacitación en prácticas de construcción, liderazgo } \\
\text { comunitario, activismo y negociación con autoridades públicas. } \\
\text { http://www.worldhabitatawards.org/winners-and- } \\
\text { finalists/project-details.cfm?theprojectid=98370925- } \\
\text { 15c5-f4c0-9982943d30eeecd3\&lang=01 }\end{array}$ & $\begin{array}{l}\text { Propuestas para "parques de bolsillo" a lo largo de la ciudad } \\
\text { y la verificación de terrazas y muros, entre otros, que están } \\
\text { fortalecidas por los incentivos otorgados por el Gobierno. } \\
\text { De acuerdo con la Agencia de Gestión Urbana de la ciudad } \\
\text { de México, se otorgará } 10 \% \text { de descuento en los pagos del } \\
\text { predial a aquellas personas que cuenten con espacios verdes } \\
\text { de al menos una tercera parte de la superficie del predio. } \\
\text { http://www.ecoosfera.com/2014/09/con-estos- } \\
\text { sencillos-pasos-consigue-un-descuento-en-el- } \\
\text { pago-del-predial-con-una-azotea-verde/ }\end{array}$ \\
\hline
\end{tabular}


Consiste en "asistir a la recuperación de ecosistemas que han sido degradados, dañados o destruidos"

en busca de la conservación y reposición del capital natural, así como la restitución de los servicios

ecosistémicos para su disfrute y aprovechamiento por parte de la sociedad. Esta acción incide sobre los procesos ecosistémicos que regulan los flujos de recursos limitantes, y se implementan de acuerdo con modelos de gestión adaptativa. Para lograr el tema ecológico es necesario la integración del conocimiento científico, de criterios socioeconómicos, del escenario cultural en el que se realiza la intervención y de la sensibilización de sus habitantes como usuarios directos de los ecosistemas a restaurar; convirtiéndose en una herramienta valiosa para los contextos informales que dependen de las condiciones del área para su éxito ecológico (TEEB, 2010)

Bottom up-Referentes

Clickarvore-(Río de Janeiro).

Promueve la recuperación de los bosques con la participación directa de los ciudadanos. Con una amplia red de socios, como viveros, patrocinadores, organizaciones no gubernamentales $y$, especialmente, de los usuarios de Internet. Se presenta este proyecto como referencia, por ser visto como una oportunidad para que las comunidades se organicen y accedan a este tipo de fondos para hacer restauración forestal orientada a la recuperación de la integridad ecológica de los ecosistemas, con especies nativas que a su vez se benefician de los servicios derivados de la reforestación.

https://www.sosma.org.br/projeto/clickarvore/
Top down-Referentes

Restauración ecológica y relocalización de viviendas-(Colombia).

Cercano al Parque Ecológico Distrital Entre Nubes (Peden) se vive un proceso de asentamiento informal. La ciudad declaró el área que rodea el barrio como ambientalmente frágil, y todo el barrio, que estaba en riesgo de deslizamiento, se relocalizó (Correa, 2011) y se transformó en un área natural por medio de una restauración ecológica. Las agencias estatales a cargo del proyecto integraron exitosamente a la comunidad en el proceso de relocalización, e incentivaron a los habitantes a trabajar con el Estado para elegir su nuevo hogar, sirviendo como guardias para evitar posibles reasentamientos.

http://www.gfdrr.org/sites/gfdrr/files/publication/ preventive_resettlement_LAC_experiencesDS150.pdf

El espacio público define la calidad de la ciudad, porque indica la calidad de vida de la gente y la cualidad de la ciudadanía de sus habitantes. Es donde ocurre la interacción social y natural para el uso, goce y disfrute de los ciudadanos. Es donde se construye sociedad, donde tiene lugar la relación e intercambio entre las personas (Alcaldía

Mayor de Bogotá et al., 2014). Estos espacios presentan diversidad de formas, dimensiones, funciones y características ambientales, con espacios de circulación y tránsito, recreación y deporte, reunión, contemplación, entre otros.

Bottom up-Referentes

Herbanisation-(Ciudad del Cabo).

Es un espacio de acceso abierto, de calles con jardines medicinales. El proyecto apunta a paisajes urbanos verdes en zonas económicamente marginadas, al tiempo que contribuye a la subsistencia de los herbolarios locales Rasta / Khoi, y a volver a conectar a los miembros de la comunidad con las plantas medicinales.

http://livelihoods.org.za/projects/herbanisation
Top down-Referentes

Vertedero de basura Gorai-(Ciudad del Cabo).

Es un gran parque verde de 19 ha, que antes era un botadero de basura, y que se ha convertido en uno de los espacios más concurridos y que ofrece las mejores vistas de la ciudad. Además, este proceso ha revalorizado el precio de las viviendas y ha dado muchos beneficios de salud pública y de estilo de vida a sus residentes.

http://fadfest.cat/website/el-gorai-dumpsite-closure-debombai-guanyador-del-city-to-city-barcelona-fad-award/ 
Según Gurrutxaga y Lozano (2007), la conectividad ecológica o funcional se define como la capacidad del territorio para permitir los desplazamientos de los organismos entre las teselas con recursos (Taylor, Fahrig, Henein y Merriam, 1993). Constituye una propiedad del territorio para una especie determinada o para un grupo funcional de especies con requerimientos ecológicos similares y capacidad dispersiva (del Barrio, Simón, Cuadrado, Sánchez, Ruiz y García, 2000).

Al interior de la ciudad se cuenta con elementos de conectividad naturales como rondas de quebradas, cerros, parques, entre otros. También con conectividad construida como plazas, parques y zonas verdes, que también ayudan a consolidar espacios de relación urbana con la biodiversidad. Los corredores en ciudades tienen gran importancia, pues muchas especies enfrentan reducciones en sus rangos territoriales por el cambio climático. La movilidad disminuye la probabilidad de extinción (Alcaldía de Medellín et al., 2014).

Bottom up-Referentes
Parque e Instituto Sitiê-(Río de Janeiro).
La misión es transformar áreas degradadas en espacios públicos
sustentables, que además de servir a su comunidad en cuanto a
educación, es hoy un refugio de frenética vida para la comunidad,
donde se puede contemplar pájaros, mariposas y pequeños monos,
caminar o correr. Incluye una huerta que ya ha producido 700 kilos
de verduras, plantas aromáticas y frutas para sus habitantes.

http://www.parquesitie.org/

Top down-Referentes

BIONET-(Ciudad del Cabo)

Es un esfuerzo para proteger un hotspot de biodiversidad mundial. Se utilizaron metodologías de planificación de conservación para definir la mejor configuración de una Red de Biodiversidad (BioNet). Se puso de relieve el papel especial de los humedales y cursos de agua, así como el papel de los corredores identificados para garantizar la conectividad entre hábitats remanentes.

https://www.capetown.gov.za/en/EnvironmentalResourceManagement/ functions/BiodivManagement/Pages/BiodiversityNetwork.aspx

\section{Herramienta número13 - Política pública}

Un paso para acercar la ciencia y la política es reconocer que ha sucedido una evolución muy rápida en el desarrollo y el entendimiento del concepto de biodiversidad, y de los procesos que la afectan. Se requiere una pedagogía desde la ciencia hacia la política, para que los tomadores de decisiones puedan consultar de manera adecuada la ciencia (Andrade y Wills, 2010).

Muchos de los planes de acción y regulaciones normativas que se crean no se ejecutan de manera continua debido, entre otros factores, a lo errático de las políticas públicas o al margen de autonomía de los tomadores de decisiones. Sin embargo, son destacables los avances en los procesos de consulta y participación ciudadana en los proyectos de planeación y desarrollo, aunque tanto la ciudadanía como los organismos de gobierno aceptan que se debe mejorar sustancialmente la forma en que estos procesos se conducen, para que la interacción genere un círculo virtuoso de gobernabilidad y gobernanza (Alcaldía de Medellín et al., 2014).

$$
\text { Bottom up-Referentes }
$$

Work With Us: Community-driven research inspiring change -(siete comunidades alrededor del mundo)

Tuvo como objetivo llevar los puntos de vista de los que están en la pobreza a quienes toman decisiones y tienen voto significativo en la política mundial. Por ejemplo, produjo un documental con el propósito de utilizar experiencias reales para mostrar por qué es necesario el diálogo con los grupos marginados y cómo los procesos participativos pueden generar falta de visión contextual, y cómo esto contribuye a la agenda de la política en la construcción de relaciones de trabajo más equitativas.

http://www.participate2015.org/2014/08/11/documentary-filmmaking-connecting-policymakers-people-living-poverty/

\section{Top down-Referentes}

PGIBSE-Propuesta para la gestión integral de la biodiversidad y servicios ecosistémicos-(Medellín)

La propuesta busca ser un aporte para la ciudad y la región con base en la generación de conocimiento y en las acciones realizadas en conservación de la biodiversidad y servicios ecosistémicos, y propone un marco estratégico y operativo para su implementación. Se trata, esencialmente, de un esfuerzo por capitalizar las experiencias, aprendizajes y resultados obtenidos en años recientes en Medellín y por dinamizar los mecanismos necesarios para la apropiación ciudadana del patrimonio vital, susceptible de preservación, restauración y uso sostenible.

https://www.medellin.gov.co/biodiversidad/ 


\section{Conclusiones y recomendaciones}

Como hemos visto, la conservación de la biodiversidad es un asunto controversial cuando se trata de ecosistemas urbanos dominados por las sociedades (Dearborn y Kark, 2010). Esta controversia se debe a que las percepciones, definiciones, relaciones y valoraciones acerca de la biodiversidad son diferentes entre cada uno de los habitantes de la ciudad, por lo que el planteamiento de los enfoques de biodiversidad urbana y servicios ecosistémicos son un punto de partida para entender la integralidad de cada uno de ellos y su posterior aplicación como criterios y herramientas de planeación (ver Tabla 5).

- Gran parte de la expansión urbana se dará en regiones con baja capacidad económica y en hotspots de biodiversidad. Ya que este patrón de crecimiento no es aleatorio y esa duplicación poblacional urbana tiene un claro patrón geográfico focalizado, se puede llegar a proponer cómo usar el kit de herramientas a futuro, adaptándolo a las condiciones particulares de la respectiva región.

Del análisis comparativo de las tres ciudades, podemos entender la relación que cada una tiene con su entorno, en las dinámicas y lógicas territoriales, expresado en forma de datos e indicadores (ver Tabla 6). Hay factores determinantes como la extensión de la ciudad que da cabida a las áreas urbanas, protegidos, informales, entre otras; o el número de habitantes que condicionan la expansión de la ciudad. Algunos hallazgos relevantes de esta comparación se mencionan a continuación:

Tabla 5.

Síntesis de los enfoques de la biodiversidad urbana y los servicios ecosistémicos urbanos

Biodiversidad urbana

Riqueza, abundancia, composición y distribución de las interacciones en hábitats

\begin{tabular}{c|c|c}
\hline Percepciones y actitudes de los ciudadanos & Cultural & Psicológicos, cognitivos, simbólicos e intelectuales \\
\hline Calidad de vida & Social & Bienestar humano \\
\hline Nivel de importancia / recursos & Económico & Bienes y servicios / costo evitado \\
\hline Resiliencia y resistencia & Cambio climático & Valor seguro \\
\hline Conocimiento y toma de decisiones & Político & Reconocimiento y toma de decisiones \\
\hline Enfoque integrado de planificación urbana & Planeación urbana & Herramientas espaciales / análisis multicriterio \\
\hline Herramienta para la gestión del territorio & Colombia & El país es heterogéneo, dinámico, \\
complejo y conflictivo
\end{tabular}

Servicios ecosistémicos urbanos

Enfoques

Funciones ecológicas

Científico

Fuente: elaboración propia (2015) 
Ficha síntesis de la comparación entre Río de Janeiro, Ciudad del Cabo y Medellín

\begin{tabular}{|c|c|c|c|c|}
\hline & & Río de Janeiro & Ciudad del Cabo & Medellín \\
\hline \multirow{13}{*}{$\begin{array}{l}\mathscr{0} \\
\text { 흠 } \\
\text { 윰 } \\
\text { 흗 }\end{array}$} & Año de fundación de la ciudad $\left(\mathrm{km}^{2}\right)$ & 1.565 & 1.652 & 1.616 \\
\hline & Extensión de la ciudad $\left(\mathrm{km}^{2}\right)$ & 1.225 & 2.461 & 380 \\
\hline & Área urbana $\left(\mathrm{km}^{2}\right)$ & 645 & 446 & 105 \\
\hline & Área rural $\left(\mathrm{km}^{2}\right)$ & 580 & 2.014 & 270 \\
\hline & Área informal $\left(\mathrm{km}^{2}\right)$ & 106 & 18,14 & 13 \\
\hline & Densidad poblacional (hab/km²) & 4.781 & 1.529 & 3.001 \\
\hline & Vivienda TOTAL & 1.883 .636 & 1.068 .572 & 791.467 \\
\hline & Habitantes & 6.320 .446 & 3.740 .025 & 2.464 .322 \\
\hline & Habitantes en condiciones de pobreza & 1.390 .498 & 635.804 & 461.708 \\
\hline & IDH & 0,80 & 0,82 & 0,61 \\
\hline & PIB & 176.630 & 58.863 & 43.462 \\
\hline & Espacio público por habitante ( $\left.\mathrm{m}^{2} / \mathrm{hab}\right)$ & 58 & 160 & 3,8 \\
\hline & Áreas protegidas urbanas (\%) & 30 & 26 & 7 \\
\hline \multirow{8}{*}{$\begin{array}{l}\frac{0}{\pi} \\
\frac{0}{0} \\
\frac{0}{0} \\
\frac{10}{0} \\
\frac{0}{0}\end{array}$} & Ecosistemas & Mata Atlántica & Región floral del Cabo & Biodiversidad urbana \\
\hline & Plantas & 20.000 & 3.350 & 2.603 \\
\hline & Mamíferos & 270 & 41 & 76 \\
\hline & Aves & 992 & 250 & 485 \\
\hline & Anfibios & 372 & 18 & 30 \\
\hline & Reptiles & - & 48 & 44 \\
\hline & Insectos & - & 111 & 1.346 \\
\hline & Peces & 350 & 24 & 44 \\
\hline \multirow{3}{*}{ 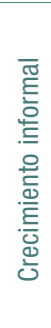 } & Población en condicione de pobreza (\%) & 22,00 & 17,00 & 18,74 \\
\hline & Razones del crecimiento informal & $\begin{array}{l}\text { Necesidad de vivir cerca } \\
\text { al lugar de trabajo por } \\
\text { las oportunidades que } \\
\text { genera la ciudad en } \\
\text { cuanto a empleo }\end{array}$ & $\begin{array}{l}\text { Migración desde Cabo } \\
\text { Oriental por pobreza y } \\
\text { desigualdad en busca de } \\
\text { mejor calidad de vida }\end{array}$ & $\begin{array}{c}\text { Presiones de } \\
\text { grupos armados / } \\
\text { desplazamiento por } \\
\text { violencia }\end{array}$ \\
\hline & $\begin{array}{c}\text { Denominación a los asentamientos informales } \\
\text { desde cada ciudad }\end{array}$ & Favela & Shack & Comuna \\
\hline
\end{tabular}

Fuente: elaboración propia (2015)

- El área urbana total de la ciudad representa un $52 \%$ para Río de Janeiro, $27 \%$ para Medellín, y $18 \%$ para la ciudad del Cabo.

- De ese porcentaje, el área informal que ocupa cada urbe corresponde al $16 \%$, $4,07 \%$ y el $12.38 \%$ de asentamientos informales, respectivamente.

- Podría decirse que Río de Janeiro es la ciudad que más presión ejerce sobre su entorno pues alberga hasta 6,3 millones de habitantes con una densidad de $4.781 \mathrm{hab} / \mathrm{km}^{2}$ (casi duplica la población de Ciudad del Cabo que tiene el doble en extensión).

- De esa población total, los habitantes que viven en asentamientos informales corresponden al $22 \%$ en Río de Janeiro, al $18 \%$ en Medellín y al $17 \%$ en Ciudad del Cabo. 
- El índice de desarrollo humano (IDH) en las ciudades de Río de Janeiro y en Ciudad del Cabo son los más altos en comparación con las ciudades más desarrolladas. Este índice se mide por: vida larga y saludable, educación y nivel de vida digna (United Nations Development Programme [UNDP] 2014). Según el Informe sobre Desarrollo Humano 2014 de la UNDP algunos barrios pueden presentar unos índices altísimos en barrios como Gávea (0.970) en Rio de Janeiro, comparables con los de Australia. Al contrario de los contextos informales en donde el IDH es tan bajo como el de Guinea Ecuatorial, como por ejemplo en el barrio Complexo do Alemão (0,711).

- El PIB en Río de Janeiro es el más alto del análisis, y en comparación con las 300 principales ciudades del mundo por PIB en 2014 (Parilla, Trujillo, Berube y Ran, 2014) se ubica en el puesto 67 de la lista, mientras que Ciudad del Cabo se encuentra en la posición 201 y Medellín en el 249. Estos datos sin duda están relacionados directamente con el nivel de oportunidades que generan estas ciudades en cuanto a empleo y calidad de vida.

- En cuanto a los datos de la biodiversidad que albergan las ciudades, es impactante la relación entre extensión de la ciudad y el número de especies. En el caso de Medellín el número de especies registradas es muy alto, lo que puede significar que los esfuerzos de estudio, muestreo y recolección de datos en esta ciudad han sido significativos. Hay que considerar sin embargo, que no fue posible encontrar datos de especies propias de la ciudad de Río de Janeiro más allá del ecosistema completo de la Mata Atlántica.
- Finalmente, en el tema de crecimiento informal, se destacan las razones de desplazamiento, ya sea por oportunidades de empleo, calidad de vida o como último recurso debido a la violencia en su lugar de origen. Es necesario prever los escenarios futuros de la expansión urbana, en especial el crecimiento espontáneo, al considerar, tanto el crecimiento de la población que habita en la ciudad, como lo nuevos habitantes que están por llegar.

- En el análisis de los criterios y herramientas de las ciudades se encontraron tres conclusiones contrastantes:

- Primero, al hacer la revisión de las principales directrices de planeación de las ciudades hay un sesgo acerca de los temas ambientales, dirigidos exclusivamente a contaminación, saneamiento, agua potable, clima y riesgos ante desastres naturales (temas abióticos). Aunque sí profundiza acerca de la informalidad y pobreza en las ciudades nunca se menciona el término biodiversidad, una evidencia cercana de este vacío son las herramientas que ofrece el Departamento Nacional de Planeación de Colombia en su informe Sistema de Ciudades (Departamento Nacional de Planeación [DNP], 2012). Adicionalmente, de los pocos proyectos exitosos que se han desarrollado en materia de asentamientos precarios, por alguna razón, han sido descontinuados (Favela de Bairro, PRIMED, entre otros).

- Segundo, se encontró herramientas similares en las tres ciudades analizadas que responden teóricamente a una visión integradora de ciudad (ZEE: Zonificación Ecológica Económica; IMEP: Política de Integración Económica Municipal; EEP: Estructura Ecológica Principal) pero que 
se quedan sin soporte ecológico, de planificación real, social, cultural y de educación a la hora de implementarlo localmente como acciones, además de ser dependientes de los periodos de gobierno y de la visión de sus gobernantes.

- Tercero, la gran oportunidad que ofrecen las ciudades para ser centros de biodiversidad (CBD, 2012) por la riqueza natural que poseen, por ser centros de evolución y adaptación, por contribuir significativamente a la calidad de vida urbana y en especial de los barrios marginales, por ser en algunas ocasiones el único contacto directo que experimentan muchas personas con la biodiversidad, por ser el principal demandante de recursos naturales, por albergar a los mismos tomadores de decisiones y políticos, por mencionar algunas.

El compromiso para la conservación de la biodiversidad urbana debe comenzar con el gobierno local. Por lo que la inclusión de la sociedad civil y de grupos de interés son vitales en las iniciativas de políticas gubernamentales locales para la gestión efectiva de la biodiversidad (Elander et al., 2005). Además, dado que los grupos de interés y actores locales tienen una influencia directa sobre esta gestión, los mecanismos de política deben diseńarse e implementarse en conjunto con iniciativas sociales, con el fin de crear redes adaptativas y policéntricas (Barthel et al., 2005), y resaltar en este aspecto la educación ambiental fundamental para la toma de decisión de sus habitantes. Este análisis encontró que el elemento integrador de la biodiversidad urbana y el crecimiento informal se da en la planeación urbana con la propuesta de "acciones locales para la biodiversidad en contextos informales" (ver Figura 12), compuestas por un kit de herramientas.
Figura 12.

Esquema de integración de la biodiversidad urbana y el crecimiento informal por medio de la planeación urbana

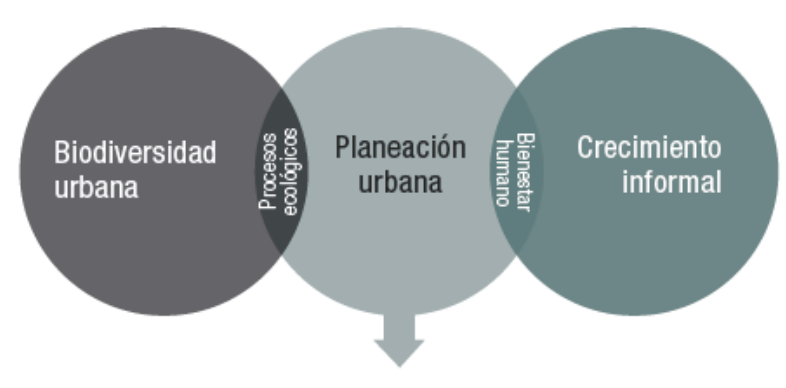

Acciones locales para la biodiversidad en contextos informales

Fuente: elaboración propia (2015)

, De los 900 millones de personas que viven en barrios marginales, el patrón de distribución por continentes evidencia que en África el $61,7 \%$ vive en asentamientos precarios, en Asia el $30 \%$ y en América Latina el $24 \%$ (UN-Hábitat, 2014), mientras que en Europa, Norteamérica y Oceanía no existen cifras. Esto puede ser una motivación para seguir estudiando las ciudades alrededor de estos continentes y ver qué variables demográficas explican la diversidad desde top down y ver la implementación local de cada acción en ciudades desde bottom up. Estos porcentajes podrían aportar en un futuro criterios de selección para estudiar ciudades y categorizarlas; y también, comprobar si las herramientas aplican en diferentes contextos. Además, al reconocer los 26 tipos de acciones (13 herramientas top down y 13 bottom up), en futuros trabajos de investigación es indispensable evaluar cuáles de estas herramientas son factibles según el contexto y variables de la ciudad. Se recomienda usar variables como la proporción entre el área urbana, rural e informal, el espacio público efectivo, el porcentaje de áreas urbanas protegidas, los habitantes en condiciones de pobreza y las razones para que exista el crecimiento informal en cada ciudad. 
- Aparte de revisar las ciudades en sus aspectos idiosincráticos específicos, es pertinente también en un futuro hacer un análisis de los múltiples actores que habitan el territorio (para las herramientas que se proponen desde el flujo bottom up) ya que las competencias entre ellos cambian al igual que quién los implementa, los interviene, los usa y quiénes se afectan (plan de acción e implementación). Esto es esencial para que las acciones propuestas se vuelvan operativas.

, La idea es continuar fortaleciendo la investigación con el análisis de otras ciudades, para seguir construyendo más propuestas de acciones locales y ampliar el kit de herramientas para que cualquier habitante, organización, grupo, secretarías, planeadores, gobernantes y demás puedan tener a la mano un abanico de oportunidades y referentes exitosos de cómo integrar el desafío que constituye la pobreza y la degradación de nuestros ecosistemas.

\section{Bibliografía}

Alberti, M., Marzluff, J, Shulenberger, E., Bradley, G., Ryan, C. y Zumbrunnen, C. (2003). Integrating Humans into Ecology: Opportunities and Challenges for Studying Urban Ecosystems. BioScience, 53(12), 1169-1179.

Alberti, M. (2005). The Effects of Urban Patterns on Ecosystem Function. International Regional Science Review, 28(2), 168-192.

Alcaldía de Medellín, Secretaría de Medio Ambiente, Parque Explora, Instituto de Investigación de Recursos Biológicos Alexander von Humboldt, Jardín Botánico de Medellín, Parques Nacionales Naturales de Colombia, Sociedad Antioquena de Ornitología. (2014). Propuesta de gestión integral de biodiversidad y servicios ecosistémicos para Medellin. Recuperado de https:// www.medellin.gov.co/servicios/siamed_portal/ siamed/documentos/Digital/4600048433\%20 de $\% 202013 \% 20 \% 20 L i b r o \% 20$ Propuesta $\% 20$ para $\% 20$ la $\% 20$ gestion $\% 20$ integral $\% 20 \mathrm{de} \% 20$ la\%20biodiversidad.pdf

Alcaldía Mayor de Bogotá D. C., Secretaría Distrital de Ambiente, Secretaría Distrital de Hábitat, Secretaría Distrital de Planeación (2014). Documento de politica pública de ecourbanismo y construcción sostenible de Bogotá. Recuperado de http://www.sdp.gov.co/portal/page/portal/ PortalSDP/Normativa/ProyectosDecreto/Politica_Publica_Ecourbanismo/DTS_PPECS_ V5_140526_1.pdf

Andrade, G., Mesa, C., Ramírez, A. y Remolina, F. (1 de junio de 2008). Estructura ecológica principal y áreas protegidas de Bogotá. Recuperado de http://oab.ambientebogota.gov.co/es/ con-la-comunidad//estructura-ecologica-principal-y-areas-protegidas-de-bogota

Andrade, G. y Wills, E. (2010). Tipos, modos de generación y gobernanza del conocimiento para la gestión de la biodiversidad. Ambiente y Desarrollo, 14(27), 55-78.

Arellano, L. y Halffter, G. (2003). Gamma Diversity: Derived from and a Determinant of Alpha Diversity and Beta Diversity. An Analysis of Three Tropical Landscapes. Acta Zoologica Mexicana, (90), 27-76.

Azqueta, D., Alviar, M., Domínguez, L. y O'ryan, R. (2007). Introducción a la economía ambiental. Madrid: MacGraw Hill.

Barrico, L., Azul, A., Moais, M., Coutinho, A., Freitas, H. y Castro, P. (2012). Biodiversity in Urban Ecosystems: Plants and Macromycetes as Indicators for Conservation Planning in the City of Coimbra (Portugal). Landscape and Urban Planning, 106(1), 88-102. 
Barthel, S., Colding, J., Elmqvist, T. y Folke, C. (2005). History and Local Management of a Biodiversity-Rich, Urban Cultural Landscape. Ecology and Society, 10(2), 10.

Bejarano, P. (2014). Historia ambiental y recuperación integral de los territorios asociados a quebradas y ríos en Bogotá (caso Chapinero). Recuperado de http://www.gwp.org/Global/GWP-SAm_Files/Publicaciones/Externas/libro_quebradas_ chapinero_20junio_small.pdf

Bello, J., Báez, M., Gómez, M., Orrego, O. y Nägele, L. (2014). Biodiversidad 2014. Estado y tendencias de la biodiversidad continental de Colombia. Recuperado de http://reporte.humboldt. org.co/biodiversidad/descargas/2014/IAvH_Biodiversidad_2014.pdf

Boyer, T. y Polasky, S. (2004). Valuing Urban Wetlands: a Review of Non-Market Valuation Studies. Wetlands, 24(4), 744-755.

Carrizosa, J. (2003). Colombia de lo imaginario a lo complejo. Reflexiones y notas sobre ambiente, desarrollo y paz. Bogotá: Universidad Nacional de Colombia.

Carrizosa, J. (2006). Desequilibrios territoriales y sostenibilidad local: conceptos, metodologías y realidades. Bogotá: Universidad Nacional de Colombia.

Carrizosa, J. (2014). Colombia compleja. Bogotá: Jardín Botánico José Celestino Mutis.

Centro de Estudios Urbanos y Ambientales [Urbam]. (2013). Rehabitar la montaña. Recuperado de https://issuu.com/universidadeafit/docs/rehabitar-monta_a

Convention on Biological Diversity [CDB]. (2012). Cities and Biodiversity Outlook: Action and Policy: a Global Assessment of the Links between Urbanization, Biodiversity and Ecosystem
Services. Montreal: Secretariat of the Convention on Biological Diversity.

Chan, K., Satterfield, T. y Goldstein, J. (febrero, 2012). Rethinking Ecosystem Services to Better Address and Navigate Cultural Values. Ecological Economics, 74, 8-18.

Chaparro, L. y Terradas, J. (2009). Ecological Services of Urban Forest in Barcelona. Recuperado de https://www.itreetools.org/resources/reports/ Barcelona $\% 20$ Ecosystem $\% 20$ Analysis.pdf

Chapin III, F., Zavaleta, E., Eviner, V., Naylor, R., Vitousek, P., Reynolds, H., y Mack, M. (2000). Consequences of Changing Biodiversity. Nature, 405(6783), 234-242.

Christie, M., Fazey, I., Cooper, R., Hyde, T. y Kenter, J. (2012). An Evaluation of Monetary and Non-Monetary Techniques for Assessing the Importance of Biodiversity and Ecosystem Services to People in Countries with Developing Economies. Ecological Economics, 83, 67-78.

Chiesura, A. (2004). The Role of Urban Parks for the Sustainable City. Landscape and Urban Planning, 68(1), 129-138.

Cilliers, S. (2010). Social Aspects of Urban Biodiversity-An Overview. En N. Müller., P. Werner. y J. Kelcey. (eds.), Urban Biodiversity and Design. (pp. 81-100). Oxford: Wiley-Blackwell.

Cincotta, R., Wisnewski, J. y Engelman, R. (2000). Human Population in the Biodiversity Hotspots. Nature, 404(6781), 990-992.

Correa, E. (2011). Preventive Resettlement of Populations at Risk of Disaster: Experiences from Latin America. Washington: Global Facility for Disaster Reduction and Recovery.

Cowling, R., Egoh, B., Knight, A., O’Farrell, P., Reyers, B., Rouget, M. y Wilhelm-Rechman, A. 
(2008). An Operational Model for Mainstreaming Ecosystem Services for Implementation. Proceedings of the National Academy of Sciences, 105(28), 9483-9488.

Daily, G. y Ellison, K. (2002). The New Economy of Nature and the Marketplace: The Quest to Make Conservation Profitable. Washington: Island Press.

Del Barrio, G., Simón, J., Cuadrado, A., Sánchez, E., Ruiz, E. y García, R. (2000). Aproximación para estimar la conectividad regional de las redes de conservación. V Congreso nacional de medio ambiente: comunicaciones técnicas. Congreso llevado a cabo en el Colegio Oficial de Físicos, Madrid, España.

De Groot, R. (1992). Functions of Nature, Evaluation of Nature in Environmental Planning, Management and Decision Making. Groningen: Wolters-Noordhoff.

De Groot, R., Wilson, M. y Boumans, R. (2002). A Typology for the Classification, Description and Valuation of Ecosystem Functions, Goods and Services. Ecological Economics, 41(3), 393-408.

De Groot, R., Alkemade, R., Braat, L., Hein, L. y Willemen, L. (2010). Challenges in Integrating the Concept of Ecosystem Services and Values in Landscape Planning, Management and Decision Making. Ecological Complexity, 7(3), 260-272.

De Oliveira, J., Balaban, O., Doll, C., Moreno-Peñaranda, R., Gasparatos, A., Iossifova, D. y Suwa, A. (2011). Cities, Biodiversity and Governance: Perspectives and Challenges of the Implementation of the Convention of Biological Diversity at the City Level. Biological Conservation, 144(5), 1302-1313.

De Oliveira, J., Shih, Wan-yu., Moreno-Peñaranda, R. y Phillips, A. (2014). Integrating
Biodiversity with Local and City Planning: The Experience of the Studios in the Development of Local Biodiversity Strategies and Action Plans. Tokio: United Nations University Institute for the Advanced Study of Sustainability.

Dearborn, D. y Kark, S. (2010). Motivations for Conserving Urban Biodiversity. Conservation Biology, 24(2), 432-440.

Departamento Nacional de Planeación [DNP]. (2012). Sistema de ciudades: una aproximación visual al caso colombiano. Bogotá: Autor.

Doornbos, M. (2001). Good Governance: The Rise and Decline of a Policy Metaphor. The Journal of Development Studies, 37(6), 93-108.

El Siouf, M. (2013). Sustainable Urban Development Challenges: a Global Perspective. Recuperado de https:/www.chalmers.se/en/areas-of-advance/ builtenvironment/news/Documents/Mohammed\%20El\%20Sioufi\%20-\%20Sustainable\%20 urban $\% 20$ development $\% 20$ challenges $\% 20$ $-\% 20 \mathrm{a} \% 20$ global\%20perspective.pdf

Elander, I., Alm, E., Malbert, B. y Sandström, U. (2005). Biodiversity in Urban Governance and Planning: Examples from Swedish Cities. Planning Theory \& Practice, 6(3), 283-301.

Elmqvist, T., Alfsen, C. y Colding, J. (2008). Urban Systems. En S. Jorgensen. y B. Fath. (eds.). Encyclopedia of Ecology. (pp. 3665-3672) Oxford: Elsevier.

Elmqvist, T., Fragkias, M., Goodness, J., Güneralp, B., Marcotullio, P., McDonald, R. y Wilkinson, C. (2013). Urbanization, Biodiversity and Ecosystem Services: Challenges and Opportunities. Dordrecht: Springer-Verlag.

Escobedo, F., Kroeger, T. y Wagner, J. (2011). Urban Forests and Pollution Mitigation: Analyzing Ecosystem Services and Disservices. Environmental pollution, 159(8), 2078-2087. 
Faeth, S., Bang, C. y Saari, S. (2011). Urban Biodiversity: Patterns and Mechanisms. Annals of the New York Academy of Sciences, 1223(1), 69-81.

Goldberg, K., Kula, S. y Mhlalisi, M. (2009). The Water Dialogues: Cape Town Case Study. Cape Town: The Water Dialogues.

Gómez-Baggethun, E. y Barton, D. (2013). Classifying and Valuing Ecosystem Services for Urban Planning. Ecological Economics, 86, 235245.

Gurrutxaga San Vicente, M. y Lozano, P. (2007). Criterios para contemplar la conectividad del paisaje en la planificación territorial y sectorial. Alicante: Universidad de Alicante, Instituto Universitario de Geografía.

Haase, D., Larondelle, N., Andersson, E., Artmann, M., Borgström, S., Breuste, J. y Kabisch, N. (2014). A Quantitative Review of Urban Ecosystem Service Assessments: Concepts, Models, and Implementation. Ambio, 43(4), 413433.

Haines-Young, R. y Potschin, M. (2013). Common International Classification of Ecosystem Services. Recuperado de http://unstats.un.org/unsd/ envaccounting/seeaLES/egm/Issue8a.pdf

Hooper, D., Chapin III, F., Ewel, J., Hector, A., Inchausti, P., Lavorel, S. y Schmid, B. (2005). Effects of Biodiversity on Ecosystem Functioning: a Consensus of Current Knowledge. Ecological Monographs, 75(1), 3-35.

Local Governments for Sustainability [ICLEI]. (2010). Local Action for Biodiversity Guidebook: Biodiversity Management for Local Governments. En M. Laros. y F. Jones. (eds.), ICLEI-Local Governments for Sustainability. (pp. 1-168). Cape Town: Autor.
International Council for Science [Icsu], United Nations Educational, Scientific and Cultural Organization [Unesco], United Nations University [UNU]. (2008). Ecosystem Change and Human Well-being. Research and Monitoring.Priorities $\mathrm{Ba}$ sed on the Millennium Ecosystem Assessment. Recuperado de http://www.icsu.org/publications/ reports-and-reviews/ecosystem-change-report/ ICSU-UNESCO-UNU_Ecosystem_Report.pdf

Ignatieva, M. (2010). Design and Future of Urban Biodiversity. Recuperado de http://www. fh-erfurt.de/urbio/httpdocs/content/documents/ Urbio2008_Keynote_Ignatieva.pdf

Johnson, E. y Klemens, M. (eds.). (2005). Nature in Fragments: the Legacy of Sprawl. Nueva York: Columbia University Press.

Kattán, G. y Valenzuela, L. (2008). Poblaciones: las unidades básicas de la conservación. En G. Kattán y L. Naranjo. (eds.), Regiones biodiversas. Herramientas para la planificación de sistemas regionales de áreas protegidas. (pp. 33-50) Recuperado de http://elti.fesprojects.net/2011Corridors1Colombia/regiones_biodiversas.pdf

Kinzig, A., Warren, P., Martin, C., Hope, D. y Katti, M. (2005). The Effects of Human Socioeconomic Status and Cultural Characteristics on Urban Patterns of Biodiversity. Ecology and Society, 10(1), 23.

Kremen, C. (2005). Managing Ecosystem Services: what do we Need to Know about their Ecology? Ecology Letters, 8(5), 468-479.

Lovasi, G., Quinn, J., Neckerman, K., Perzanowski, M. y Rundle, A. (2008). Children Living in Areas with More Street Trees have Lower Prevalence of Asthma. Journal of Epidemiology and Community Health, 62(7), 647-649.

Lugo, A. (2014). Tropical Cities are Diverse and Deserve More Social-Ecological Attention. Ecology and Society, 19(3), 24. 
Maas, J., Verheij, R., Groenewegen, P., De Vries, S. y Spreeuwenberg, P. (2006). Green Space, Urbanity, and Health: how Strong is the Relation? Journal of Epidemiology and Community Health, 60(7), 587-592.

Martín-López, B., González, J., Díaz, S., Castro, I y García-Llorente, M. (2007). Biodiversidad y bienestar humano: el papel de la diversidad funcional. Ecosistemas, 16(3). 69-80.

Martínez-Alier, J. (2005). El ecologismo de los pobres. Barcelona: Icaria.

McCarty, J. (2001). Ecological Consequences of Recent Climate Change. Conservation Biology, 15(2), 320-331.

McKinney, M. (2002). Urbanization, Biodiversity, and Conservation The Impacts of Urbanization on Native Species are Poorly Studied, but Educating a Highly Urbanized Human Population about These Impacts can Greatly Improve Species Conservation in all Ecosystems. BioScience, 52(10), 883-890.

McPherson, E., Nowak, D., Heisler, G., Grimmond, S., Souch, C., Grant, R. y Rowntree, R. (1997). Quantifying Urban Forest Structure, Function, and Value: the Chicago Urban Forest Climate Project. Urban Ecosystems, 1(1), 49-61.

Millenium Ecosystem Assessment [MEA]. (2005). Ecosystems and Human Well-being: Synthesis. Washington: World Resources Institute.

Meehl, G. y Tebaldi, C. (2004). More Intense, more Frequent, and Longer Lasting Heat Waves in the 21 st Century. Science, 305(5686), 994997.

Millard, A. (2010). Cultural Aspects of Urban Biodiversity. En N. Müller., P. Werner. y J. Kelcey. (eds.), Urban Biodiversity and Design. (pp. 5680). Oxford: Wiley-Blackwell.
Ministerio de Ambiente y Desarrollo Sostenible. (2012a). Criterios ambientales para el diseño $y$ construcción de vivienda urbana. Recuperado de http://www.minambiente.gov.co/images/ AsuntosambientalesySectorialyUrbana/pdf/Sello_ambiental_colombiano/cartilla_criterios_ amb_diseno_construc.pdf

Ministerio de Ambiente y Desarrollo Sostenible. (2012b). Politica Nacional para la Gestión Integral de la Biodiversidad y los Servicios Ecosistémicos (PNGIBSE). Bogotá: Ministerio de Ambiente.

Mitchell, R. y Popham, F. (noviembre, 2008). Effect of Exposure to Natural Environment on Health Inequalities: an Observational Population Study. The Lancet, 372(9650), 1655-1660.

Mittermeier, R., Myers, N., Mittermeier, C. y Robles, P. (1999). Hotspots: Earth's Biologically Richest and Most Endangered Terrestrial Ecoregions. Ciudad de México: CEMEX.

Müller, N., Werner, P. y Kelcey, J. (eds.). (2010). Urban biodiversity and design. Oxford: Wiley-Blackwell.

Niemelä, J. (1999). Ecology and Urban Planning. Biodiversity and Conservation, 8(1), 119131.

Nowak, D. (2010). Urban Biodiversity and Climate Change. En N. Müller., P. Werner. y J. Kelcey. (eds.), Urban Biodiversity and Design. (pp. 101-117). Oxford: Wiley-Blackwell.

Parilla, J., Trujillo, J., Berube, A. y Ran, T. (2014). Global MetroMonitor 2014: An Uncertain Recovery. Recuperado de https://www. brookings.edu/wp-content/uploads/2015/01/ bmpp_gmm_final.pdf

Pearce, D. (2007). Do we Really Care about Biodiversity? Environmental and Resource Economics, 37(1), 313-333. 
Programa de las Naciones Unidas para el Desarrollo [PNUD]. (2014). Sostener el progreso humano: reducir vulnerabilidades y construir resiliencia. Recuperado de. http://hdr.undp.org/sites/default/files/hdr14-summary-es.pdf

Rincón-Ruíz, A., Echeverry-Duque, M., Piñeros, A., Tapia, C., David, A., Arias-Arévalo, P. y Zuluaga, P. (2014). Valoración integral de la biodiversidad y los servicios ecosistémicos: Aspectos conceptuales y metodológicos. Bogotá: Instituto de Investigación de Recursos Biológicos Alexander von Humboldt.

Rockström, J., Steffen, W., Noone, K., Persson, Å., Chapin III, F., Lambin, E. y Foley, J. (2009). Planetary Boundaries: Exploring the Safe Operating Space for Humanity. Ecology and Society, $14(2), 32$.

Salas, G. y Ortega, C. (2005). Significado biológico de las diversidades alfa, beta y gamma. En G. Halffter. (ed.), Sobre diversidad biológica: el significado de las diversidades alfa, beta y gamma. (pp. 5-18). España: GORFI.

Sánchez, F., Díaz, A. y Formisano, M. (2003). Conflicto, violencia y actividad criminal en Colombia: un análisis espacial. Bogotá: CEDE.

Savard, J., Clergeau, P. y Mennechez, G. (2000). Biodiversity Concepts and Urban Ecosystems. Landscape and Urban Planning, 48(3), 131-142.

Schipper, J., Chanson, J., Chiozza, F., Cox, N., Hoffmann, M., Katariya, V. y Baillie, J. et al., (2008). The Status of the World's Land and Marine Mammals: Diversity, Threat, and Knowledge. Science, 322(5899), 225-230.

Schwarz, N., Lautenbach, S. y Seppelt, R. (2011). Exploring Indicators for Quantifying Surface Urban Heat Islands of European Cities with MODIS Land Surface Temperatures. Remote Sensing of Environment, 115(12), 3175-3186.
Shwartz, A., Turbé, A., Simon, L. y Julliard, R. (2014). Enhancing Urban Biodiversity and its Influence on City-Dwellers: An Experiment. Biological Conservation, 171, 82-90.

Steffen, W., Richardson, K., Rockström, J., Cornell, S., Fetzer, I., Bennett, E. y Sörlin, S. (2015). Planetary Boundaries: Guiding Human Development on a Changing Planet. Science, 347(6223). Doi: 10.1126/science.1259855.

Soares, F. (2012). Planeta Ciudad: ecología urbana y planificación de ciudades medias de Brasil. (Tesis doctoral). Recuperado de https://es.scribd. com/doc/110692845/Planeta-Ciudad-Ecologia-Urbana-y-Planificacion-de-Ciudades-Medias-de-Brasil

Soares, F., Essy, C., Sanz, J., da Silva, F., Albertin, R. y Santos, J. (2015). Ecología urbana: la ciencia interdisciplinaria del planeta ciudad. Desenvolvimento em Questão, 13(32), 6-20.

Soares, F., Santos, J., Sanz, J., Silva, F. y Albertín, R. (2016). Tipología socio-ambiental de las ciudades medias de Brasil: aportes para un desarrollo urbano sostenible. Urbe. Revista Brasileira de Gestão Urbana, 8(2), 272-287.

Taylor, P., Fahrig, L., Henein, K. y Merriam, G. (1993). Connectivity is a Vital Element of Landscape Structure. Oikos, 68(3), 571-573.

The Economics of Ecosystems and Biodiversity [TEEB]. (2010). The Economics of Ecosystems and Biodiversity for Local and Regional Policy Makers. Geneva: Progress Press.

The Economics of Ecosystems and Biodiversity [TEEB]. (2011). TEEB Manual for Cities: Ecosystem Services in Urban Management. Geneva: Progress Press.

The Erfurt Declaration [Urbio]. (2008). The Erfurt Declaration-Urbio 2008. Recuperado de 
https://www.bfn.de/fileadmin/MDB/documents/ presse/Erfurt_Declaration_Urbio_2008.pdf

Thomas, C., Cameron, A., Green, R., Bakkenes, M., Beaumont, L., Collingham, Y. y Hughes, L. (2004). Extinction Risk from Climate Change. Nature, 427(6970), 145-148.

Tyrväinen, L., Pauleit, S., Seeland, K. y De Vries, S. (2005). Benefits and Uses of Urban Forests and Trees. En C. Konijnendijk., K Nillsson., T. Randrup. y J. Schipperijn. Urban Forests and Trees. (pp. 81-114). Heidelberg: Springer Berlin Heidelberg.

Tzoulas, K., Korpela, K., Venn, S., Yli-Pelkonen, V., Kaźmierczak, A., Niemelä, J. y James, P. (2007). Promoting Ecosystem and Human Health in Urban Areas Using Green Infrastructure: A literature Review. Landscape and Urban Planning, 81(3), 167-178.

United Nations [UN]. (2005). Objetivos de desarrollo del Milenio: informe de 2005. Recuperado de http://mdgs.un.org/unsd/mdg/Resources/Static/Products/Progress2005/mdg2005 progresschart.pdf

United Nations [UN]. (2008). World Urbanization Prospects: The 2007 Revision. Nueva York: Department of Economic and Social Affairs, Population Division.

United Nations [UN]. (2014). World Urbanization Prospects: the 2014 Revision Population Database. Nueva York: Autor.

United Nations, Department of Economic and Social Affairs, Population Division [UN-DESA]. (2014). World Urbanization Prospects: The 2014 Revision. Recuperado de https://esa.un.org/ unpd/wup/

United Nations Development Programme [UNDP]. (2014). Informe sobre desarrollo humano
2014 sostener el progreso humano: reducir vulnerabilidades y construir resiliencia. Recuperado de http://hdr.undp.org/sites/default/files/ hdr14-summary-es.pdf

United Nations Population Fund [UNFPA]. (2011). Informe regional de población en América Latina y el Caribe 2011: invertir en Juventud. Recuperado de http://lac.unfpa.org/ sites/lac.unfpa.org/files/pub-pdf/Informejuventud2011.pdf

UN-Habitat (2010). Estado de las ciudades de América Latina y el Caribe. Recuperado de http:// www.cinu.mx/minisitio/Informe_Ciudades/SOLACC_2012_web.pdf

UN-Habitat. (2013). Metropolis Nonformal-Anticipation. Recuperado de http://uni.unhabitat. org/metropolis-nonformal-anticipation/

UN-Habitat. (2014). Voices from Slums. Recuperado de http://unhabitat.org/wp-content/ uploads/2014/03/ED-Statement_English.pdf

United Nations Statistics Division, y Millennium Development Goals [UNSD] [MDG]. (2012). Población en asentamientos informales ubicadas en zonas urbanas por paises, 2012. http://www.devinfo.org/libraries/aspx/home.aspx

Urbina-Cardona, J. y Agudelo, C. (2011). Políticas ambientales urbanas. Reconocimiento de servicios ecosistémicos. Recuperado de http://www. academia.edu/728295/Pol\%C3\%ADticas_ambientales_urbanas_Reconocimiento_de_servicios_ecosist $\%$ C3\%A9micos

Voigt, A. y Wurster, D. (2015). Does Diversity Matter? The Experience of Urban Nature's Diversity: Case Study and Cultural Concept. Ecosystem Services, 12, 200-208.

Walker, B. y Salt, D. (2006). Resilience Thinking. Sustaining Ecosystems and People in a Changing World. Washington: Island Press. 
Walther, G., Post, E., Convey, P., Menzel, A., Parmesan, C., Beebee, T. y Bairlein, F. (2002). Ecological Responses to Recent Climate Change. Nature, 416(6879), 389-395.

Werthmann, C. (2011). Metrópolis non formal. En Universidad Eafit (Presidencia), Conferencia en Congreso Ambientes Urbanos. Medellín, Colombia.

Wilby, R. y Perry, G. (2006). Climate Change, Biodiversity and the Urban Environment: a Critical Review Based on London, UK. Progress in Physical Geography, 30(1), 73-98.

Wilkinson, C., Sendstad, M., Parnell, S. y Schewenius, M. (2013). Urban Governance of Biodiversity and Ecosystem Services. En Autores. Urbanization, Biodiversity and Ecosystem Services: Challenges and Opportunities. (pp. 539-587). Dordrecht: Springer Netherlands.
Williams, J. (2012). Humans and Biodiversity: Population and Demographic Trends in the Hotspots. Population and Environment, 34(4), 510-523.

Young, O. (1996) Introduction. The Effectiveness of International Environmental Governance Systems, En O. Young., G. Demko. y K. Ramakrishna. (eds.), Global Environmental Change and International Governance. (pp. 1-30). Londres: University Press of New England.

Yokohari, M., Takeuchi, K., Watanabe, T. y Yokota S. (2000). Beyond greenbelts and zoning: A new planning concept for the environment of Asian mega-cities: Landscape and Urban Planning

Zoning: a New Planning Concept for the Environment of Asian Mega-Cities. Landscape and Urban Planning, 47(3), 159-171. 